\title{
Time-course of host cell transcription during the HTLV-1
}

\section{transcriptional burst}

3 Short title: Host cell transcription during the HTLV-1 plus-strand burst

4

5 Helen Kiik ${ }^{1 \pi}$, Saumya Ramanayake ${ }^{1 \pi}$, Michi Miura $^{1, \# a}$, Yuetsu Tanaka², Anat Melamed ${ }^{1}$,

6 Charles R.M. Bangham ${ }^{1 *}$

7

$8{ }^{1}$ Department of Infectious Diseases, Faculty of Medicine, Imperial College London, London,

9 United Kingdom

102 Department of Infectious Disease and Immunology, Okinawa-Asia Research Center of 11 Medical Science, Faculty of Medicine, University of the Ryukyus, Nishihara, Okinawa, Japan \#a Current Address: Department of Microbiology, Kawasaki Medical School, Kurashiki,

13 Okayama, Japan

14 * Corresponding author

15 E-mail: c.bangham@imperial.ac.uk

16 I These authors contributed equally to this work. 


\section{Abstract}

19 The human T-cell leukemia virus type 1 (HTLV-1) transactivator protein Tax has pleiotropic

20 functions in the host cell affecting cell-cycle regulation, DNA damage response pathways and apoptosis. These actions of Tax have been implicated in the persistence and pathogenesis of HTLV-1-infected cells. It is now known that tax expression occurs in transcriptional bursts of the proviral plus-strand, but the effects of the burst on host transcription are not fully understood. We carried out RNA sequencing of two naturally-infected T-cell clones transduced with a Tax-responsive Timer protein, which undergoes a time-dependent shift in fluorescence emission, to study transcriptional changes during successive phases of the HTLV-1 plusstrand burst. We found that the transcriptional regulation of genes involved in the NF-KB pathway, cell-cycle regulation, DNA damage response and apoptosis inhibition were immediate effects accompanying the plus-strand burst, and are limited to the duration of the burst. The results distinguish between the immediate and delayed effects of HTLV-1 reactivation on host transcription, and between clone-specific effects and those observed in both clones. The major transcriptional changes in the infected host T-cells observed here, including NF-kB, are transient, suggesting that these pathways are not persistently activated at high levels in HTLV-1-infected cells. The two clones diverged strongly in their expression of genes regulating the cell cycle. Up-regulation of senescence markers was a delayed effect of the proviral plus-strand burst and the up-regulation of some pro-apoptotic genes outlasted the burst. We found that activation of the arylhydrocarbon receptor (AhR) pathway enhanced and prolonged the proviral burst, but did not increase the rate of reactivation. Our results also suggest that sustained plus-strand expression is detrimental to the survival of infected cells. 


\section{Author Summary}

42

43 Human T-cell leukemia virus type $1(\mathrm{HTLV}-1)$ causes a lifelong infection that results in disease in $\sim 10 \%$ of cases. The HTLV-1 transactivator protein Tax is involved in both the persistence of infected host cells, and the pathogenesis of HTLV-1 infection. tax is transcribed from the plus-strand of the provirus, and tax expression is not constitutive, but limited to transcriptional bursts. How these bursts affect host cell transcription is not completely understood. Here, we studied the temporal changes in host transcription during successive phases of the plus-strand burst in two naturally-infected T-cell clones. We found that the deregulation of genes involved in Tax-associated processes, including NF-KB activation, cell-cycle regulation, DNA damage response and suppression of apoptosis, coincided with the early phase of the plus-strand burst: these transcriptional effects appear to be limited to the duration of the proviral plusstrand expression. Regulation of cell-cycle genes diverged between the clones, demonstrating the heterogeneity of naturally-infected cells. We observed a pro-apoptotic response, which outlasted the burst and may indicate increased risk of apoptosis following the burst. Finally, we observed that AhR activity regulated the intensity and duration of the burst, but not the dynamics of reactivation. 


\section{Introduction}

60

61

Human T-cell leukaemia virus type I (HTLV-1) is a pathogenic retrovirus that mainly infects CD4 $^{+}$T-cells, causing a lifelong infection in the host. An estimated 10 million people in the world are living with the virus; between $5 \%$ and $10 \%$ of infected hosts develop one of the associated diseases Adult T-cell leukaemia (ATL) or HTLV-1-associated myelopathy/tropical spastic paraparesis (HAM/TSP) [1,2].

The sense and antisense strands of the provirus encode the viral transactivator Tax protein and HBZ (HTLV-1 bZIP protein), respectively: these two proteins promote the proliferation and survival of HTLV-1-infected cells, and both have been implicated in the development of ATL $[3,4]$.

Tax potently modulates proviral and cellular transcription, which has contrasting consequences in stimulating cell cycle progression and proliferation [5-10], or causing temporary cell cycle arrest and senescence [11-14]. HTLV-1-infected or Tax-transduced cells are also protected from apoptosis $[15,16]$. Transcriptional down-regulation of pro-apoptotic factors [17,18], and up-regulation of anti-apoptotic factors [19-22] are likely to contribute to the protective activity of Tax. By contrast, there is evidence that Tax promotes apoptosis [2325], and Tax-expressing cells are more susceptible to cell death following exogenous DNA damage $[26,27]$. Tax expression impairs the functions of p53 [28], causes genome instability, induces double-strand DNA breaks, and inhibits DNA damage-response pathways [5,29-32]. HBZ opposes many functions of Tax including proviral transcription, likely mediated by its interactions with the transcription factors CREB, c-JUN and CBP/p300, and by suppression of NF-KB [33-37].

The mechanisms of the pleiotropic effects of HTLV-1 proviral expression remain unclear, and while many important findings have been made with tax-transfected cell lines or long-term in vitro transformed cell lines, it is a long-standing question how these observations apply to untransformed, naturally-infected T-cells. It is now clear that the tax and $H B Z$ genes are not constitutively transcribed at the single-cell level in naturally-infected cells in vivo, but rather in 
86 intermittent bursts $[20,38,39]$, and it is not understood how the diverse observations on cell

87 proliferation and apoptosis are related to these bursts. We studied two naturally-infected CD4+

88 T-cell clones competent in Tax expression (3.60 and TBX4B), isolated by limiting dilution from

89 peripheral blood mononuclear cells (PBMCs) of HTLV-1-infected subjects [40], to quantify host

90 and viral transcription during proviral reactivation. Each clone was stably transduced with a

91 reporter construct, under the control of a Tax-responsive promoter, that expresses a

92 fluorescent protein - the Timer Protein - which undergoes a time-dependent change in

93 emission frequency. This approach made it possible to separate the plus-strand transcriptional

94 burst into successive phases. Here we report the changes in transcription in the host CD4 ${ }^{+} \mathrm{T}$

95 cell accompanying the onset and the progression through the HTLV-1 plus-strand burst. 


\section{Results}

98

99

100

101

102

103

104

105

106

107

108

109

110

111

112

113

114

115

116

117

118

119

120

121

122

Fig 1. The principle behind Tax-induced Timer protein expression. (A) Tax-responsive reporter construct containing the Timer protein gene Fast-FT. (B) Schematic of Timer protein expression during progression of the HTLV-1 plus-strand burst. (C) Representative gating strategy used to flow-sort four cell populations for RNAseq analysis. (D) Tax expression in each respective Timer population, quantified by intracellular staining.

The HTLV-1 plus-strand burst begins with transcription of tax, resulting in a positive-feedback loop of potent activation of plus-strand transcription by Tax protein [44]. Expression of Tax protein is a surrogate for the proviral plus-strand transcriptional burst, and in this study the subsequent induction of the Timer protein by Tax was used to distinguish successive phases of the plus-strand burst. The clones were flow sorted into four populations based on the fluorescence of the Timer protein during spontaneous proviral expression, representing 
respectively silent proviruses and the early phase (blue), mid-phase (blue-red) and late phase (red) of the plus-strand burst (Fig 1). Following termination of the burst and decay of remaining red fluorescence of the Timer protein, the cells re-enter the silent (non-fluorescent) doublenegative (DN) state.

PolyA-selected RNA samples from each clone were sequenced. Clone 3.60 has a 202 bp deletion that lies in the coding region of env on the plus-strand and the 3'UTR of $h b z$ on the minus-strand (S1 Fig). The deletion did not impair the expression of Tax protein, as shown by the expression of the Timer protein, the up-regulation of both the Timer and the plus-strand transcripts of the provirus in the RNA-seq data (Fig 2A). The expression trajectories of both the HTLV-1 plus-strand and the Tax-responsive Timer transcripts were closely similar in both clones (Fig 2A).

Fig 2. RNA-seq validates the experimental setup. (A) Expression of HTLV-1 plus- and minus-strands quantified by RNA-seq in each Timer population. Statistical significance was determined by the likelihood-ratio test (LRT). FDR-corrected p-value < 0.01; ns - not significant. (B) Principal component analysis (PCA) bi-plot of the RNA-seq data in each clone.

Principal component analysis of the respective Timer phases (Fig 2B) indicated distinct profiles of gene expression during the successive phases of proviral reactivation. Time-series differential expression analysis of the phases of proviral expression identified 10048 significantly differentially expressed (DE) genes in clone 3.60, and 4798 DE genes in clone TBX4B, respectively representing $57 \%$ and $29 \%$ of expressed host genes (Likelihood-ratio test (LRT); FDR adjusted p-value < 0.01) (S1-S2 Data). HTLV-1 plus-strand and the Taxresponsive Timer were among the top most significantly DE genes in each clone (S1-S2 Data) and HTLV-1 plus-strand was the most significantly up-regulated gene in the early burst (Blue) population in each clone, with a log2 fold change (LFC) of 9.60 in clone 3.60 and a LFC of 
up-regulated gene during onset of proviral expression in TBX4B was PNPLA3 (Figs S2-S3); the integration site of HTLV-1 in TBX4B lies between exons 2 and 3 of PNPLA3.

The trajectory of proviral minus-strand expression had no consistent relationship with plusstrand expression and differed between the two clones (Fig 2A). However, the expression of minus-strand expression in each clone closely resembled that of SP1, a known regulator of its transcription [45] (S3 Fig).

Further validating the Timer Protein reporter system used, NF-KB transcription factor genes REL, RELB, NFKB1, NFKB2 were up-regulated in both clones (Fig 2A). The up-regulation of genes known to be expressed in response to Tax including IL2RA, IL13 and JUND [46-49] was confirmed in both clones, and the Tax-repressed target LCK [50] was down-regulated (Fig 2A). The expression of KAT2B (P/CAF), which interacts with Tax to increase expression from the viral LTR [51], was unexpectedly down-regulated in both clones (S3 Fig). To examine in detail the transcriptional effects shared by the two clones, the overlap of 3851 genes differentially expressed in both clones was analyzed through K-means clustering. Using $k=5$ produced five clusters depicting respectively genes up-regulated during the early burst in each clone, genes up-regulated with a delayed peak (in mid-burst) in each clone, genes downregulated in each clone, and two clusters showing genes with opposite trajectories (Fig 3A).

Fig 3. Genes deregulated in both clones separate into clone-independent and clone-

specific clusters. (A) K-means clustering of 3851 shared significantly DE genes. Statistical significance was determined by LRT. FDR-corrected $p$-value $<0.01$. The top 10 genes in each cluster, based on mean rank of sorted $\mathrm{p}$-values, are listed on the right of the panel. The mean expression trajectory is coloured as a yellow or blue line representing upregulation and downregulation, respectively. (B) ORA of K-means clusters with the Hallmarks gene set from The Molecular Signatures Database (MSigDB). Statistical significance was determined by Fisher's exact test in g:Profiler. FDR-corrected p-value $<0.05$.

177 To infer functional characteristics of these clusters, an over-representation analysis (ORA) of 178 the MSigDB Hallmark gene set [52] was performed. This analysis identified "TNFa signalling 179 via NF-KB" as the most significant term in two clusters: immediately up-regulated genes during 
plus-strand expression (Fig 3 cluster 1) and genes with a delayed peak of expression during mid-burst (Fig 3 cluster 2). TNF itself was downregulated (S3 Fig). "Hypoxia" was similarly an enriched term in the up-regulated cluster 1; HIF1A itself was upregulated (S3 Fig). Other enriched terms in cluster 1 were "IL2-STAT5 signaling" and "Inflammatory response", the latter was enriched in cluster 2 as well. "TNFa signalling via NF-KB" and "Hypoxia" were also enriched when all differentially expressed genes in each clone were clustered and analyzed separately (S4B Fig cluster 1 and S4D Fig cluster 1).

Cluster 3 consisted of genes down-regulated in both clones and was enriched for "Allograft rejection", "IL6/JAK/STAT3 signaling" and "Interferon gamma signaling" (Fig 3). "Interferon-Y response" was significant in both the delayed up-regulated gene cluster 2 and the downregulated gene cluster 3 (Fig 3).

The fourth cluster contained genes that were differentially expressed in both clones, but these genes were down-regulated in clone 3.60 and up-regulated in TBX4B. This cluster included cell-cycle-related genes with Hallmark terms "G2M checkpoint, E2F targets", "Mitotic spindle". Cell-cycle-related genes are analysed in more detail below.

Cluster 5, which represented genes up-regulated in clone 3.60 and down-regulated in clone TBX4B, did not result in any significantly enriched Hallmark terms (Fig 3).

\section{Clone-specific association between proviral expression and} cell cycle genes.

We investigated how the contrasting observations of Tax induced cell proliferation or cell cycle arrest and senescence relate to the transcriptional control of host genes in naturally infected T-cells during successive phases of proviral reactivation.

For a systematic analysis of genes associated with different cell cycle stages, cyclically expressed genes were obtained from the online database Cyclebase 3.0 (https://cyclebase.org/CyclebaseSearch). All differentially expressed genes from each clone were separated into distinct groups of genes, based on the Cyclebase classification, each 
group with peak expression in different cell cycle phases (G1, G1/S, G2, G2/M, M). The results

(Fig 4A) show that genes associated with peak expression during different phases of cell-cycle progression were down-regulated in clone 3.60 during plus-strand expression, but were upregulated in TBX4B. These groups contained genes with established roles in DNA replication including GINS2, CHAF1B, as well as phosphatases CDC25A, CDC25C, kinases PLK1, $A U R K B, N E K 2$, mitotic-spindle-related genes PRC1, BIRC5, CDCA8, and the known marker of cell proliferation MKI67. In clone TBX4B, expression of G1-S phase-related genes peaked during the early burst and G2-M phase genes peaked during the mid-burst (Fig 4A).

Fig 4. Divergent association between proviral plus-strand expression and genes related

to the cell cycle. (A) Trajectories in each infected clone of differentially expressed Cyclebase 3.0 genes associated with G1, G1/S, S, G2, G2/M and M phases of the cell cycle. (B) Trajectories of cyclins, CDKs and transcription factors. Y-axis: normalized counts on $\log _{10}$-scale. Statistical significance was determined by LRT. FDR-corrected p-value $<0.01$; ns - non-significant.

The trajectories of $\mathrm{G} 1$ phase cyclin-dependent kinase CDK6 and cyclins CCND1, CCND2, CCND3, which mediate entry into the cell cycle, were similar in the two clones (Fig 4B). CDK6, but not $C D K 4$, was significantly up-regulated in both clones and highest during the early burst (Blue) of proviral plus-strand expression. Both CCND1 and CCND2 were significantly upregulated in clone 3.60 , whereas the expression of CCND1 was much lower in TBX4B; CCND2 showed a trend of up-regulation, which was not significant. CCND3 was significantly down-regulated during the early burst in both clones. CDK2 (active in G1/S and S phase) was up-regulated in both clones during early and midburst (Fig 4B). By contrast, the G1/S phase cyclins CCNE1 and CCNE2 differed between the clones. CCNE1 was expressed at a low level, and its subsequent up-regulation was delayed until mid-burst in 3.60; its trajectory was inconclusive in TBX4B. By contrast, CCNE2 was significantly up-regulated only in TBX4B. More importantly, the G1/S phase transcription factor 
234 The pattern of cyclin expression progressively diverged between the clones as the cell cycle

235 advanced (Fig 4B). The S-phase genes CCNA1 and CCNA2 were down-regulated in clone

236 3.60, whereas CCNA2 was up-regulated in TBX4B. Similar contrasts in expression were

237 observed in mitotic cyclins CCNB1, CCNB2, CDK1 kinase, and the mitotic phase transcription

238 factor FOXM1. The expression level of many of these genes returned to the value seen in the silent phase by late burst, when proviral expression is terminating. This divergent gene expression of cell cycle regulators between the two clones demonstrates that two naturally

241 infected T-cell clones can fundamentally differ in their response to proviral plus-strand 242 expression.

III. Immediate up-regulation of genes involved in the DNA damage response is followed by senescence markers

Several functions of Tax are associated with genomic instability, repression of DNA damage response and induction of senescence [53]. Our results indicated significant deregulation of TP53, which differed between two infected clones (Fig 5). This trajectory resembled that of the divergent cell-cycle mediators in Fig 4B. By contrast, we observed up-regulation of another p53 family member (TP63) and many known p53 targets: GADD45B, GADD45A, GADD45G, CDKN1A (p21), and the main DNA-damage sensor of global genome nucleotide excision repair (GG-NER) XPC. We also observed up-regulation of CETN2 and RAD23B, which together with XPC form the recognition complex of GG-NER [54]. Previously it has been reported that NER is suppressed by the direct up-regulation of PCNA induced by Tax $[55,56]$. PCNA was deregulated in both clones; however, the expression trajectories differed between the clones. The trajectories of two kinases activated by double-strand DNA breaks, ATM and $A T R$, differed in their response to plus-strand expression. ATM was significantly downregulated in both clones, whereas ATR was up-regulated in clone 3.60 with a similar trend in TBX4B. 
CDKN1A, which displayed a delayed up-regulation (Fig 5), belongs to the CIP/KIP family of CDK inhibitors. The CIP/KIP family gene CDKN1C (p57) was significantly up-regulated during the early transcriptional burst, with a higher level of expression in 3.60. The INK4 family of CDK inhibitor members, $C D K N 2 A(\mathrm{p} 16)$ and $C D K N 2 B(\mathrm{p} 15)$ were significantly down-regulated in both clones during proviral expression. In addition to CDKN1A, another senescence marker GLB1 was up-regulated, peaking during mid-burst. These results indicate that DNA damage response pathways were activated during the burst, and the initial mitogenic signalling in G1 (Fig 4) was accompanied by the parallel down-regulation of G1-phase CDK inhibitors.

Fig 5. Up-regulation of DNA damage response and senescence markers. Gene expression apoptotic mediators and down-regulation of apoptotic effectors

Previous results have shown that Tax expression can promote cell death [23-27]. However, Tax has also been described to suppress apoptosis and this protection is transferable to cells not actively expressing Tax $[15,16,20]$. We observed a strong deregulation of key genes involved in the intrinsic and extrinsic apoptosis pathways during the plus-strand burst [57]. At the onset of the plus-strand burst, there was immediate downregulation of at least one of the pore-forming apoptotic factor genes in each clone (Fig 6). BAX was significantly downregulated during the early-burst in clone 3.60 , whereas a similar (yet non-significant) trend was seen in TBX4B. However, BAK1 expression was sharply down-regulated only in clone TBX4B. The expression level of $B A K 1$ in clone 3.60 remained low during both the silent and early burst phases, but rebounded in the mid-burst and late burst. 
Fig 6. Temporal patterns of pro- and anti-apoptotic factors. Gene expression trajectories of antiand pro-apoptotic BCL2 family members, extrinsic apoptosis factors, anti-apoptotic and caspase genes. Y-axis: normalized counts on $\log _{10}$-scale. Statistical significance was determined by LRT. FDR-corrected $p$-value $<0.01$; ns - not significant

Both clones showed strong up-regulation of the anti-apoptotic genes $B C L 2, B C L 2 L 1$ and $B C L 2 L 2$, which encode inhibitors of the pore-forming BCL2 family proteins (Fig 6). However, the pro-apoptotic genes PMAIP1 (NOXA), BCL2L11 (BIM) and BMF were also immediately up-regulated. The pro-apoptotic gene BID was significantly up-regulated during the early-burst in clone 3.60. Curiously, both PMAIP1 and BCL2L11 sustained a high expression throughout proviral reactivation and remained high in the termination phase. was up-regulated during the mid-burst in 3.60 yet down-regulated in clone TBX4B (Fig 6). Their cognate ligands FASLG and TNFSF10 were strongly down-regulated. Although the intrinsic pathway initiator CASP9 was up-regulated only in clone 3.60 , the deathinducing signaling complex (DISC) member genes CASP8 and CASP10, which are initiators of the extrinsic pathway, were down-regulated during the early burst. The primary effector CASP3 was significantly downregulated over the course of proviral expression in clone 3.60 , with a similar (albeit non-significant) trajectory in clone TBX4B. The inhibitors of apoptosis proteins capable of impairing caspase-mediated apoptosis - BIRC2, BIRC3 and CFLAR (cFLIP) - were strongly up-regulated in both clones.

A significant down-regulation of the granzyme genes GZMA and GZMB was also observed (S3 Fig). These genes are associated with cytotoxic activity of $\mathrm{CD}^{+} \mathrm{T}$-cells and NK cells; their function in $\mathrm{CD} 4^{+} \mathrm{T}$ cells is incompletely understood.

These results showed that during the plus-strand burst the principal apoptotic effectors were down-regulated, and the apoptosis inhibitors up-regulated, in both extrinsic and intrinsic pathways. By contrast, a sustained expression of pro-apoptotic factor genes PMAIP1 and 
317 The factors that regulate the spontaneous onset of expression of the provirus are not fully understood, but include the proviral integration site [58], cell stress [20,59], AHR signaling [60], and ubiquitinylation of histone $2 \mathrm{~A}$ lysine 119 by polycomb repressive complex 1 (PRC1) [61]. RING1, RYBP and KDM2B are members of the non-canonical PRC1 (ncPRC1) [62] and their expression was up-regulated during the burst (Fig 7). BMI1 (PCGF4), which is a core member of the canonical PRC1, was down-regulated in both clones (Fig 7).

Fig 7. Up-regulation of ncPRC1 members. Gene expression trajectories of ncPRC1 and canonical (CYP1A1), a product of the AhR pathway, between the early burst and late burst populations in both clones (Figs S2-S3). AhR is a transcription factor that regulates many biological processes through its activation in response to metabolic and environmental signals $[63,64]$. Following recent reports indicating enhanced HIV-1 proviral expression in response to AhR ligands in PBMCs isolated from patients on antiretroviral therapy [65] and HTLV-1 plus-strand expression in HTLV-1 infected transformed cell lines [60], we investigated the effect of AhR signalling on HTLV-1 expression in T-cell clones isolated from HTLV-1-infected individuals. 
bioRxiv preprint doi: https://doi.org/10.1101/2022.02.24 481745; this version posted February 24, 2022. The copyright holder for this preprint (which was not certified by peer review) is the author/funder, who has granted bioRxiv a license to display the preprint in perpetuity. It is made available under aCC-BY 4.0 International license.

337 Endogenous AhR ligands such as tryptophan metabolites are present in the culture medium.

338 We evaluated the effects of treatment with supplemental AhR ligands or AhR antagonists on

339 HTLV-1 proviral expression using two patient-derived T-cell clones (3.60 and 11.50).

340 Treatment with an endogenous AhR ligand, ITE [66], or a tryptophan-derived AhR ligand, FICZ

341 [67] significantly increased Tax protein expression above background levels (Fig 8A). A purine-derived AhR antagonist StemRegenin 1 (SR1) [68] and a ligand-selective antagonist

$343 \mathrm{CH} 223191$ [69] each substantially decreased Tax protein expression (Fig 8A). Transcription

344 of the HTLV-1 plus-strand (tax) (Fig 8B) and AhR target genes (CYP1A1 and CYP1B1) (Fig

345 8D-E) was significantly induced by AhR agonists and suppressed by AhR antagonists. Neither

346 AhR agonists nor antagonists altered the expression of the HTLV-1 minus-strand (sHBZ) (Fig $3478 \mathrm{C})$.

348 Fig 8. AhR signalling enhances HTLV-1 plus-strand expression. (A) Two patient-derived HTLV-

3491 infected T -cell clones were treated with AhR agonists or antagonists or CYP1A1 inhibitor for 48 hours at the indicated concentrations. DMSO was used as the vehicle control. The percentage of plus-strand expressing cells among viable cells was quantified by Tax protein expression using flow cytometry. The bar plot depicts the mean and SEM from two independent experiments. Unpaired two-tailed t-tests were used to determine the significance of the difference between the vehicle control and the treatment conditions. ${ }^{*} \mathrm{P}<0.05,{ }^{* *} \mathrm{P}<0.01,{ }^{* * *} \mathrm{P}<0.001$. Expression levels of (B) tax (plus-strand), (C) sHBZ (minus-strand), AhR target genes (D) CYP1A1 and (E) CYP1B1 quantified by RT-qPCR after 24-hour treatment with DMSO, AhR activators or inhibitors or CYP1A1 inhibitor. Bar plots represent the mean and SEM from two independent experiments using two T-cell clones. ${ }^{*} \mathrm{P}<0.05$, ${ }^{* *} \mathrm{P}<$ $0.01,{ }^{* * *} \mathrm{P}<0.001,{ }^{* * *} \mathrm{P}<0.0001$ (unpaired two-tailed t-test). Proviral $(\mathrm{F})$ silencing and $(\mathrm{G})$ reactivation kinetics in response to treatment with AhR agonists and antagonists. The data depict mean \pm SEM from two independent experiments using a single clone.

The significant upregulation of CYP1A1 expression observed during the late burst raised the question whether CYP1A1 itself contributes to the termination of HTLV-1 plus-strand expression (S1-S2 Data and S2-S3 Figs). However, treatment of the cells with Khellinoflavanone 4I (IIIM-517), an inhibitor of CYP1A1 enzymatic activity [70], did not affect 
366 CYP1A1 indicated activation of the AhR pathway, but CYP1A1 itself is not directly involved in 367 the termination of HTLV-1 plus-strand burst.

368 We then investigated the effect of additional AhR ligands or inhibitors on HTLV-1 plus-strand 369 reactivation and silencing dynamics using a patient-derived HTLV-1 infected T-cell clone 370 (11.50) stably transduced with a Tax reporter construct that expresses a modified EGFP with 371 a half-life of $\sim 2 \mathrm{~h}$ (d2EGFP). In these cells, the presence of d2EGFP is a surrogate for Tax 372 protein expression. Live-cell imaging revealed that, compared with untreated cells, a greater 373 portion of provirus-expressing cells terminated Tax expression in response to treatment with 374 AhR antagonists (Fig 8F). Treatment with AhR agonists or a CYP1A1 inhibitor did not 375 substantially affect proviral silencing or reactivation kinetics (Fig 8F, G). Spontaneous proviral 376 reactivation was evident at early stages despite the presence of AhR inhibitors (Fig 8G).

377 These results indicate that enhanced AhR signalling augments and prolongs HTLV-1 plus378 strand expression but is not the sole determinant of reactivation from latency in patient-derived 379 T-cell clones. 


\section{Discussion}

It is well established that the HTLV-1 viral transactivator Tax deregulates the transcription of many host genes. Both Tax and the minus-strand-encoded HTLV-1 bZIP factor HBZ have been frequently implicated in leukemogenesis. Tax expression occurs in intermittent transcriptional bursts $[20,38]$, likely in order to limit exposure to the immune system and the cytotoxic effects of Tax protein. It remains unclear whether the impact of HTLV-1 on host transcription, including genes involved in proliferation and apoptosis are immediate and direct, or late and indirect consequences of proviral reactivation and plus-strand expression. In this study, a Tax-responsive Timer Protein construct was used to distinguish successive temporal phases of the spontaneous proviral transcriptional burst, to investigate the precise trajectory of expression of host genes involved in cell cycle regulation and apoptosis during the proviral plus-strand burst.

Two naturally-infected T-cell clones competent in the expression of Tax allowed us to identify both clone-independent and clone-dependent correlates of proviral plus-strand expression. Clone 3.60 has a deletion in the coding sequence of env on the plus-strand and in the $3^{\prime}$ UTR of the minus-strand-encoded gene HBZ (S1 Fig). This deletion does not change the predicted protein sequence of $\mathrm{HBZ}$, and the deleted sequence was absent from the HBZ expression construct used to investigate the protein-dependent and mRNA-dependent actions of $H B Z$ [71]. However, it remains possible that this deletion influences the half-life or the physiological actions of $H B Z$ mRNA.

Proviral expression deregulated a large number of host genes in each clone: 3851 genes were deregulated in both clones, which could be grouped into clusters defined by the trajectory of expression during the proviral plus-strand burst (Fig $3 \mathrm{~A})$. Tax activates both the canonical and non-canonical NF-kB pathways [72]. NF-kB pathway is persistently activated at the population level in transformed cell lines and primary ATL cells [73,74]. The present results confirm 
immediate, clone-independent NF-kB activation during proviral plus-strand expression (Fig 2A and Fig 3 cluster 1), which is followed by the likely secondary effects of NF-kB activation (Fig

4173 cluster 2); both the immediate and later effects decreased during the termination of proviral expression (Fig 3 clusters 1-2). TNF itself was downregulated (S4 Fig): the observed upregulation of genes in this enrichment term are likely to be the consequences of NF-KB activation by Tax. These observations suggest that high levels of NF-kB activation are confined to the active expression of Tax protein accompanying the plus-strand burst; constitutive activation of NF-KB may not be required for persistence in non-malignant HTLV1-infected clones. We also confirmed the immediate up-regulation of IL2RA (Fig 2A), a known target of Tax, and genes in the "IL2-STAT5 signaling" enrichment term (Fig 3 cluster 1).

There was no consistent relationship between plus-strand and minus-strand expression of the provirus within each clone or between the clones (Fig 2A). The expression trajectory of the minus-strand resembled that of $S P 1$ (S3 Fig), a known regulator of $H B Z$ expression [45]. These results suggest that it is unlikely that Tax directly regulates the expression of HBZ or vice versa, and imply that the clone-independent responses to HTLV-1 proviral reactivation observed in this study are not regulated by HBZ during the plus-strand burst.

Tax is known to up-regulate the expression of several genes involved in cell cycle progression

434 including CCND1, CCND2, CDK4, CDK6, CDK2 and E2F1 [75-80]. The present results demonstrate a clone-specific association between proviral plus-strand expression and the expression of genes involved in cell cycle regulation (Fig 3 cluster 4). There was a strong difference between the two clones in the expression of genes that peak in different cell cycle phases obtained from Cyclebase 3.0 database (Fig 4A). Increased expression of G1-phase cyclins CCND1, CCND2 and kinase CDK6 suggests that the cells are stimulated to enter the 440 cell cycle in each clone. In line with this, G1-phase CDK inhibitors CDKN2A and CDKN2B 441 were down-regulated (Fig 6). However, subsequent expression of G1/S, S and M phase genes 442 CCNE2, CCNA1, CCNA2, CCNB1, CCNB2 and CDK1, and key transcription factors that 
443 regulate the cell cycle, E2F1 and FOXM1, diverged between the clones progressively

444 throughout the cell cycle (Fig 4B). These findings are consistent with previous observations

445 on the same clones reported by [38]. Billman et al. showed that Tax-expressing cells were

446 more abundant in $\mathrm{G} 1$ phase in clone 3.60 and in G2/M phase in clone TBX4B. We note that

447 clone 3.60 also grows more slowly in cell culture. Although E2F1 is up-regulated in response

448 to Tax $[76,77]$, the diverging trajectories of E2F1 and its downstream targets indicate that the

449 transcription of E2F1 is unlikely to be directly activated by Tax (Fig 4B). These observations

450 emphasize the natural heterogeneity of HTLV-1 infected T-cells and help to reconcile

451 previously published diverging results on cell-cycle progression in HTLV-1-infected cells.

453 It has been proposed that the interplay between the effects of Tax in proliferation and the DNA damage response regulates the fate of Tax-expressing cells [53]. Tax expression causes double-strand breaks and activation of the DNA-damage response $[5,29]$; however, in the presence of additional genotoxic agents these pathways are impaired [53]. The activity of p53 is also repressed in HTLV-1-infected cells, through mechanisms that do not involve its DNAbinding activity and intracellular localization [81]. Our results show that TP53 itself is deregulated during the plus-strand burst: the trajectory differed between the clones, but expression returned to baseline in each clone after termination of the burst (Fig 5). There was consistent up-regulation of another p53 family gene, TP63, and p53 targets including the GADD45 family members, CDKN1A and XPC (Fig 5). There was immediate up-regulation of genes involved in DNA damage response during the early burst of proviral expression, including GADD45B, ATR and global genome nucleotide excision repair (GG-NER) genes RAD23B, XPC and CETN2 (Fig 5). However, ATM was down-regulated. ATR is known to respond to a wide range of DNA damage; the observed differences in expression between ATR and ATM in these clones indicates the presence of DNA damage other than doublestranded breaks. The up-regulation of DNA damage response genes was followed by the upregulation of senescence markers $C D K N 1 A$ and $G L B 1$, which peaked during the mid-burst phase (Fig 5). Up-regulation of CDKN1A (p21) associated with hyperactivation of NF-KB by 
471 Tax has been shown to cause cell senescence [14]; however, the present results indicate that

472 the up-regulation of $C D K N 1 A$ and GLB1 occurs in the mid-burst phase of persistent Tax

473 expression, yet reduces during the late phase of the burst. The results demonstrate temporal

474 separation of the DNA damage response and up-regulation of senescence-related genes

475 during the plus-strand burst, and that sustained proviral expression may result in reduced

476 proliferative capacity of HTLV-1 infected cells.

477

478 Tax has been shown to deregulate both pro-apoptotic and anti-apoptotic genes [17-22].

479 Consistent with this, both clones strongly up-regulated anti-apoptotic genes $B C L 2, B C L 2 L 1$,

480 BCL2L2, BIRC2, BIRC3, CFLAR and TNFAIP3; and down-regulated key effectors of both the extrinsic and intrinsic apoptosis pathways: either $B A X$ or $B A K 1$, and $C A S P 3$, and downregulated death receptor ligands FASLG, TNFSF10, TNF (Fig 6). Although the death receptor ligands were down-regulated, the death receptors FAS and TNFRSF10 were up-regulated in both clones (Fig 6). These observations suggest that the deregulation of genes involved in the extrinsic and intrinsic pathways is an immediate - perhaps direct - effect of Tax. Sustained expression of Tax is toxic to cells, and the up-regulation of pro-apoptotic factors can partly explain this; however, the results presented here suggest that the strong up-regulation of antiapoptotic factors can counteract the pro-apoptotic effect during proviral plus-strand expression. Curiously, we observed an up-regulation of pro-apoptotic factors PMAIP1 and $B C L 2 L 11$ that was sustained throughout the transcriptional burst and termination phases, which may pose an increased risk of apoptosis after termination of the plus-strand burst.

HTLV-1 proviral latency is associated with the PRC1-mediated ubiquitylation of histone $2 \mathrm{~A}$ lysine 119 (H2AK119ub1); inhibition of deubiquitylation represses proviral plus-strand reactivation [61]. Here, we observed the up-regulation of ncPRC1 members RING1, RYBP and $K D M 2 B$ through the early and mid-burst phases of proviral expression (Fig 7). Conversely,

497 a core component of the canonical PRC1, BMI1 (PCGF4), was down-regulated. Targeted recruitment of PRC1 to non-methylated $\mathrm{CpG}$ islands is mediated by KDM2B [82], and RYBP 
elevates the enzymatic ability of the PRC1 complex resulting in enhanced deposition of the H2AK119ub1 mark [83]. The up-regulation of these key PRC1 genes during proviral reactivation could be involved in the post-burst repression of proviral expression.

502

503 Up-regulation of genes involved in the inflammatory response and hypoxia (Fig 3, cluster 1) is consistent with the observation that cellular stress, including hypoxia, enhances proviral expression [20,59]. Although the hypoxia response observed by Kulkarni et al. was HIF-1independent, we found that HIF1A was significantly up-regulated (S3 Fig).

Constitutive high expression of $A h R$, which is up-regulated in response to Tax, has been observed in ATL cells [84]. Recently, it was shown that persistent activation of NF-KB is important for the observed AHR expression: AhR signaling sustains and drives HTLV-1 plusstrand expression and can potentiate HTLV-1 reactivation from latency [60]. Consistent with a previous report [84], we saw expression of $A H R, A R N T$ and direct targets of AhR activation (CYP1B1, NQO1) in the silent population of cells in both clones. By contrast, proviral plusstrand expression was not associated with increased expression of $A H R$, but instead was accompanied by the down-regulation of $A H R$, ARNT and down-stream genes (S3 Fig). The effects observed here of treatment with agonists or antagonists of AhR (Fig 8) and the downregulation of genes involved in the AhR pathway during spontaneous HTLV-1 proviral reactivation (S3 Fig), suggest that AhR activation enhances and prolongs proviral plus-strand expression, but $A H R$ is transcriptionally inhibited during spontaneous HTLV-1 plus-strand expression. The transcriptional inhibition of the AhR pathway during the proviral burst may limit the extent and duration of Tax expression.

HTLV-1 expression, and in particular the Tax protein, have been associated with many

524 transcriptional changes in the infected host $\mathrm{T}$ cell. The results presented here make it possible 525 to distinguish between the immediate effects of the HTLV-1 plus-strand burst on host transcription, and the delayed or secondary effects. These results also demonstrate both 
clone-dependent and clone-independent transcriptional responses of the host cell accompanying the proviral plus-strand transcription. NF-KB was activated in response to HTLV-1 reactivation and this activation was contained to the duration of the proviral burst, which suggests NF-KB-mediated effects are not persistently active in clonal populations of naturally-infected T-cells. The regulation of genes responsible for progression through the cell cycle was clone-specific, emphasising the heterogeneity of naturally HTLV-1-infected T-cells.

533 However, the up-regulation of genes involved in DNA damage recognition (GG-NER) and 534 senescence were clone-independent, and associated with active expression of the provirus. 535 Similarly, the transcriptional control of pro- and anti-apoptotic genes was consistent in the two clones and suggested a strong anti-apoptotic response that is limited to the duration of the burst; upregulation of certain pro-apoptotic genes outlasted the burst. We also observed the up-regulation of non-canonical PRC1 members, which are associated with the epigenetic regulation of the provirus [61]. In the context of these results, it will be important to verify the effects of this transcriptional regulation of host genes, on the dynamics of infected cells during and following the burst. Finally, we tested the involvement of the AhR pathway in proviral reactivation and found that while activation of the AhR pathway increased the intensity of the plus-strand burst, it did not increase the frequency of reactivation.

\section{Materials \& methods}

\section{Cell culture}

547 The HTLV-1-infected clones used in this study were CD4+CD25+CCR4+ T cells, each 548 carrying a single copy of the HTLV-1 provirus, derived from peripheral blood cells isolated 549 from HTLV-1-infected individuals as described previously [40]. The clones were cultured in 550 RPMI-1640 (Sigma-Aldrich) supplemented with 20\% fetal bovine serum (FBS), 2 mM L551 Glutamine, $50 \mathrm{IU} / \mathrm{ml}$ Penicillin, $50 \mu \mathrm{g} / \mathrm{ml}$ Streptomycin (all from ThermoFisher Scientific) and 
$552100 \mathrm{IU} / \mathrm{ml}$ human interleukin 2 (IL-2, Miltenyi Biotec). Ten micromolar integrase inhibitor,

553 Raltegravir (Selleck Chemicals) was added to the cultures to prevent secondary HTLV-1

554 infections. The cells were supplemented with IL-2 and Raltegravir twice-weekly intervals and 555 cultured at $37^{\circ} \mathrm{C}, 5 \% \mathrm{CO}_{2}$.

\section{Plasmid Generation}

557 To create pLJM1-LTR-FT, pLJM1-EGFP (Addgene 19319) was digested with Ndel and EcoRI

558 to create the vector backbone. A forward primer (5'-ATGGTGAGCAAGGGCGAG-3') and a 559 reverse primer (5'-TCGAGGTCGAGAATTCTTACTTGTACAGCTCGTCCATGC-3') with a 15 base pair overlap with vector backbone were used in a polymerase chain reaction (PCR) to generate fast Timer protein timer fragment from plasmid pFast-FT-N1 (Addgene 31910). Five tandem repeats of Tax responsive element (TRE) type 2 and an HTLV-1 promoter was amplified from WT-Luc plasmid [85] by PCR using forward (5'(GATC Biotech).

570 pLJM1-LTR-d2EGFP was generated by digesting pLJM1-EGFP with Ndel and EcoRI to

571 produce the vector backbone. A PCR incorporating a forward primer (5'-

574 with vector backbone were used to amplify destabilised enhanced green fluorescent 575 (d2EGFP) fragment from pcDNA3.3_d2eGFP plasmid (Addgene 26821). A fragment 576 containing 9 copies of TRE type 1 and TRE type 3 and an HTLV-1 promoter was amplified 577 from SMPU-18x21-EGFP plasmid [86] by PCR using forward (5'- 

GCTCACCATGGTGGCATCTCGCCAAGCTTGGATCTGT-3') primers with 15 base pair overlap with vector backbone and d2EGFP PCR product, respectively. pLJM1-LTR-d2EGFP was formed by inserting the two PCR products into the vector backbone using In-Fusion HD Cloning Kit. Sanger sequencing was used to verify the sequence of the inserts in the transfer plasmid.

\section{Lentiviral Transduction}

HEK 293T cells were seeded into $150 \mathrm{~mm}$ Corning TC-treated Culture Dishes (Corning) the day before transfection to reach an approximately $95 \%$ confluence on the day of transfection. HEK 293 T cells were co-transfected with either pLJM1-LTR-FT or pLJM1-LTR-d2EGFP, psPAX2 (Addgene 12260) and pCMV-VSV-G (Addgene 8454) plasmids using Lipofectamine 3000 (Invitrogen) following the manufacturer's protocol. Viral supernatants were harvested 24 and 52 hours post-transfection. Supernatants were centrifuged at $2000 \mathrm{rpm}$ for 10 minutes and passed through a $0.45 \mu \mathrm{m}$ syringe filter (Sartorius) to remove debris prior to concentration by ultracentrifugation at $25000 \mathrm{rpm}$ for 2 hours at $4^{\circ} \mathrm{C}$. One hundred thousand cells were spinoculated with $100 \mu \mathrm{l}$ of concentrated viral supernatant in the presence of $8 \mu \mathrm{g} / \mathrm{ml}$ polybrene and $10 \mathrm{mM}$ HEPES (Sigma-Aldrich) at $800 \mathrm{~g}, 32^{\circ} \mathrm{C}$ for 2 hours. Transduced cells were washed once and cultured in complete medium supplemented with IL-2. Three days post-transduction,

597 the cultures were supplemented with Raltegravir and Puromycin Dihydrochloride 598 (ThermoFisher Scientific) was added at $2 \mu \mathrm{g} / \mathrm{ml}$ twice a week for 14 days to select transduced cells. Timer protein or d2EGFP-positive cells were sorted by flow cytometry to obtain Timer protein or d2EGFP-expressing populations. Flow-sorted cultures returned to their steady state within two weeks of flow sorting. Replicates were grown in parallel. The cultures were maintained in $1 \mu \mathrm{g} / \mathrm{ml}$ Puromycin Dihydrochloride during the regular feeding cycle to prevent 
603 the emergence of resistance gene silent populations. The transduced clones expressing two

604 different Tax reporter systems are given in Table 1.

607

\begin{tabular}{|l|l|}
\hline Clone & Tax reporter system \\
\hline TBX4B & pLJM1-LTR-FT \\
\hline TBJ 3.60 & pLJM1-LTR-FT \\
\hline TBW 11.50 & pLJM1-LTR-d2EGFP \\
\hline
\end{tabular}

608

609 Flow cytometry analysis

610 Cells were washed once with PBS and stained with $1 \mu \mathrm{g} / \mathrm{ml}$ viability marker, LIVE/DEAD

611 fixable near-IR (ThermoFisher Scientific) for 5 minutes and washed once in FACS buffer (PBS

$612+5 \%$ FCS), and fixed for 30 minutes with fixation/permeabilisation buffer of eBioscience

613 FOXP3/Transcription Factor Staining Buffer Set (ThermoFisher Scientific). The cells were

614 then washed with permeabilisation buffer, stained with $1 \mu \mathrm{g} / \mathrm{ml}$ anti-Tax mAb (Clone LT-4) in

615 permeabilisation buffer for 30 minutes, washed twice in permeabilisation buffer, and

616 resuspended in FACS buffer. A slightly modified staining protocol was used to co-detect Tax

617 protein with timer protein. Following the staining with viability marker and subsequent wash,

618 the cells were fixed with 4\% formaldehyde (ThermoFisher Scientific) for 15 minutes, washed

619 once in FACS buffer, permeabilised with 0.1\% Triton X-100 (ThermoFisher Scientific) for 15

620 minutes, washed once with FACS buffer and stained with $1 \mu \mathrm{g} / \mathrm{ml}$ anti-Tax mAb (Clone LT-4)

621 in FACS buffer for 30 minutes. Finally, the cells were washed twice and resuspended in FACS

622 buffer. All washes and incubations were performed at room temperature for flow cytometry 
623 analysis and sorting. The cells were acquired on a BD LSRFortessa (BD Biosciences) flow

624 cytometer. FlowJo software (BD Biosciences) was used to analyse flow cytometry data.

\section{Flow sorting}

626 Live cell flow cytometry sorting under containment level 3 (CL3) conditions was performed in 627 the CL3 Cell Sorting Facility at Chelsea and Westminster Hospital in London. Cells were 628 washed once with PBS and stained with $1 \mu \mathrm{g} / \mathrm{ml}$ LIVE/DEAD fixable near-IR viability dye for 5 629 minutes, washed once and resuspended in RPMI 1640 without phenol red (ThermoFisher 630 Scientific) supplemented with $2 \%$ FCS. Viable Blue ${ }^{-} \operatorname{Red}^{-}\left(\right.$double negative, DN), Blue $^{+}$Red $^{-}$,

631 Blue $^{+}$Red $^{+}$(double positive, DP), Blue-Red ${ }^{+}$or viable d2EGFP ${ }^{+}$and d2EGFP- cells were sorted under sterile conditions using a BD FACSAria III cell sorter. Duplicate parallel cultures

633 from each timer protein Tax reporter clone were flow-sorted on the same day. RNeasy Plus

634 Micro Kit (Qiagen) was used to extract RNA from the flow-sorted timer protein sub-populations 635 following the manufacturer's protocol. RNA integrity was quantified using RNA 6000 Pico Kit 636 (Agilent) on a 2100 Bioanalyzer (Agilent).

\section{$637 \quad$ Live-cell imaging}

638 Flow-sorted proviral-expressing (d2EGFP $\left.{ }^{+}\right)$and non-expressing (d2EGFP-) cells were seeded

639 into a 96 well plate pre-coated with $1 \mathrm{mg} / \mathrm{ml}$ Poly-D-Lysine (PDL, Merck). Aryl hydrocarbon

640 receptor $(\mathrm{AhR})$ agonists and antagonists were added at concentrations indicated in Figure 8.

641 One hundred nanomolar YOYO-3 lodide (ThermoFisher Scientific) was added to label dead

642 cells. Live-cell imaging was performed using Incucyte S3 (Sartorius) live-cell imaging system

643 capturing 9 Phase contrast, green and red fluorescent images per well every 6 hours using a

$64420 x$ objective. Image analysis was performed with the "Non-adherent Cell-by-Cell" image 
645 analysis module on the Incucyte, using the parameters listed in Table 2. The percentage of

646 viable cells that were d2EGFP positive was calculated.

647 Table 2: Imaging and mask parameters used for image capturing and analysis on 648 Incucyte S3

\begin{tabular}{|c|c|c|c|c|}
\hline Channel & Target & $\begin{array}{l}\text { Exposure } \\
\text { time }\end{array}$ & $\begin{array}{l}\text { Background } \\
\text { fluorescence } \\
\text { correction } \\
\text { method }\end{array}$ & Segmentation parameters \\
\hline Phase & All cells & Not available & Not applicable & $\begin{array}{l}\text { Sensitivity }(\text { Threshold }=9, \\
\text { Background }=10, \text { Edge }=10, \\
\text { Particle area (minimum }=30 \\
\left.\mu m^{2}, \text { maximum }=\infty \mu \mathrm{m}^{2}\right)\end{array}$ \\
\hline Green & $\begin{array}{l}\text { d2EGFP+ } \\
\text { Cells }\end{array}$ & $300 \mathrm{~ms}$ & $\begin{array}{l}\text { Top-Hat }(50 \mu \mathrm{m} \\
\text { radius })\end{array}$ & Not applicable \\
\hline Red & Dead cells & $400 \mathrm{~ms}$ & $\begin{array}{l}\text { Top-Hat }(50 \mu \mathrm{m} \\
\text { radius })\end{array}$ & Not applicable \\
\hline
\end{tabular}

651 RNeasy Plus Mini kit (Qiagen) was used to extract RNA from cells cultured with vehicle control

652 (DMSO), or AhR agonists or antagonists. RNA was reverse-transcribed using Transcriptor

653 First Strand cDNA Synthesis Kit (Roche) with random hexamer primers following

654 manufacturer's instructions. A no-reverse transcriptase (RT) control was included for each

655 sample to verify the elimination of genomic DNA from RNA samples. RNA transcripts were

656 amplified with a master mix containing gene-specific primers listed in Table 3 and Fast SYBR

657 Green Master Mix (ThermoFisher Scientific) on a Viia 7 Real-Time PCR System 
658 (ThermoFisher Scientific). The relative quantification of target mRNAs was performed using 659 the LinRegPCR method [87], and the data were normalised against the internal PCR control, 18S rRNA.

\begin{tabular}{|c|c|c|c|}
\hline Target gene & Orientation & Sequence & Reference \\
\hline \multirow[t]{2}{*}{$\operatorname{tax}$} & Forward & $\begin{array}{l}\text { '- } \\
\text { CCGGCGCTGCTCTCATCCCGGT-3' }\end{array}$ & \multirow{6}{*}{ [88] } \\
\hline & Reverse & $\begin{array}{l}\text { 5'- } \\
\text { GGCCGAACATAGTCCCCCAGAG-3' }\end{array}$ & \\
\hline \multirow[t]{2}{*}{$s H B Z$} & Forward & 5'-GGACGCAGTTCAGGAGGCAC-3' & \\
\hline & Reverse & 5'-CCTCCAAGGATAATAGCCCG-3' & \\
\hline \multirow[t]{2}{*}{$18 S$} & Forward & 5'-GTAACCCGTTGAACCCCATT-3' & \\
\hline & Reverse & 5'-CCATCCAATCGGTAGTAGCG-3' & \\
\hline CYP1A1 & Forward & 5'-CACCATCCCCCACAGCAC-3' & \multirow{4}{*}{ [89] } \\
\hline & Reverse & 5'-ACAAAGACACAACGCCCCTT-3' & \\
\hline \multirow[t]{2}{*}{ CYP1B1 } & Forward & 5'-GCTGCAGTGGCTGCTCCT-3' & \\
\hline & Reverse & 5'-CCCACGACCTGATCCAATTCT-3' & \\
\hline
\end{tabular}

662

663 Statistical analysis

664 Statistical analysis was performed using GraphPad Prism (GraphPad Software) and in R [90]. 
669 and the resulting FASTQ files aggregated for each sample. FastQC (RRID:SCR_014583,

670 version 0.11.8) and MultiQC (RRID:SCR_014982, version 1.8) were used for quality 671 assessment before and after adapter and quality trimming with Trim Galore 672 (RRID:SCR_011847, version 0.6.4_dev). The STAR aligner (RRID:SCR_004463, version

673 2.7.3a)was used to align reads against a custom merged reference of the human (Ensembl100

674 GRCh38) genome [91], HTLV-1 (GenBank: AB513134) genome and the reference sequence

675 of the Timer protein. A custom gene transfer format (GTF) including coordinates for the Timer

676 protein and HTLV-1 was also supplied for STAR to transform the alignments into transcript

677 coordinates (--quantMode TranscriptomeSAM). RSEM (RRID:SCR_013027, version 1.3.1)

678 was then used for transcript quantification of stranded aligned reads ( --forward-prob 0 )[92].

\section{Differential expression analysis}

680 Tximport (RRID:SCR_016752, version 1.14.2) was used to import gene level transcript 681 abundance estimates for differential expression analysis using DESeq2 (RRID:SCR_015687, 682 version 1.32.0) in R (version 4.1.2) $[90,93,94]$. Each clone was analysed separately, and reads 683 with $<3$ counts in at least two samples were removed. The LRT was used to identify 684 significantly DE genes across all Timer protein populations; for pairwise comparisons the 685 default Wald test was used. FDR adjusted $p$-value $<0.01$ cut-off was used for both approaches 686 [95].

\section{K-means clustering}

688 K-means clustering (using MacQueen algorithm) with $k=5$ was carried out in $\mathrm{R}$ on the subset 689 of DE genes that overlapped in the two clones [90]. A joined matrix of the scaled variancestabilizing transformation (VST) transformed counts was used as input [96]. 
bioRxiv preprint doi: https://doi org/10.1101/2022 02.24 481745 this version posted February 24, 2022. The copyright holder for this preprint (which was not certified by peer review) is the author/funder, who has granted bioRxiv a license to display the preprint in perpetuity. It is made available under aCC-BY 4.0 International license.

\section{Over-representation analysis}

692 Over-representation analysis (ORA) was performed with g:Profiler (RRID:SCR_006809,

693 version 0.2.0) against the MSigDB's Hallmark gene set collection [97,52]. A custom

694 background of all genes that were subjected to differential expression testing in both clones

695 was used. 


\section{Acknowledgments}

697

698 We thank Parisa Amjadi from the CL3 Cell Sorting Facility at The Centre for Immunology and

699 Vaccinology at Imperial College London. We thank Oxford Genomics Centre for library 700 preparation and RNA Sequencing. We thank Chou-Zen Giam (Uniformed Services University)

701 for providing the SMPU-18x21-EGFP plasmid; Brigitta Stockinger (Crick Institute) for providing 702 FICZ and helpful discussions; and Sandip Bharate (Indian Institute of Integrative Medicine) for providing CYP1A1 inhibitor, IIIM-517. We thank Imperial College Research Computing

704 Service for use of the high-performance computing cluster (DOI: 10.14469/hpc/2232). 


\section{References}

706

707

708

709

710

711

712

713

714

715

716

717

718

719

720

721

722

723

724

725

726

727

728

729

730

731

732

733

734

735

736

737

738

739

1. Gessain A, Cassar O. Epidemiological Aspects and World Distribution of HTLV-1 Infection. Front Microbiol. 2012;3: 388. doi:10.3389/fmicb.2012.00388

2. Bangham CRM. Human T Cell Leukemia Virus Type 1: Persistence and Pathogenesis Annu Rev Immunol. 2018;36: 43-71. doi:10.1146/annurev-immunol-042617-053222

3. Matsuoka M, Mesnard J-M. HTLV-1 bZIP factor: the key viral gene for pathogenesis. Retrovirology. 2020;17: 2. doi:10.1186/s12977-020-0511-0

4. Mohanty S, Harhaj EW. Mechanisms of Oncogenesis by HTLV-1 Tax. Pathogens. 2020;9: 543. doi:10.3390/pathogens9070543

5. Boxus M, Twizere J-C, Legros S, Kettmann R, Willems L. Interaction of HTLV-1 Tax with minichromosome maintenance proteins accelerates the replication timing program. Blood. 2012;119: 151-160. doi:10.1182/blood-2011-05-356790

6. Lemoine FJ, Marriott SJ. Accelerated G1 Phase Progression Induced by the Human T Cell Leukemia Virus Type I (HTLV-I) Tax Oncoprotein *. J Biol Chem. 2001;276: 3185131857. doi:10.1074/jbc.M105195200

7. Neuveut C, Low KG, Maldarelli F, Schmitt I, Majone F, Grassmann R, et al. Human TCell Leukemia Virus Type 1 Tax and Cell Cycle Progression: Role of Cyclin D-cdk and p110Rb. Mol Cell Biol. 1998;18: 3620-3632. doi:10.1128/MCB.18.6.3620

8. Schmitt I, Rosin O, Rohwer P, Gossen M, Grassmann R. Stimulation of CyclinDependent Kinase Activity and G1- to S-Phase Transition in Human Lymphocytes by the Human T-Cell Leukemia/Lymphotropic Virus Type 1 Tax Protein. J Virol. 1998;72: 633640. doi:10.1128/JVI.72.1.633-640.1998

9. Sibon D, Gabet A-S, Zandecki M, Pinatel C, Thête J, Delfau-Larue M-H, et al. HTLV-1 propels untransformed CD4+ lymphocytes into the cell cycle while protecting CD8+ cells from death. J Clin Invest. 2006;116: 974-983. doi:10.1172/JCI27198

10. Asquith B, Zhang $\mathrm{Y}$, Mosley AJ, Lara CM de, Wallace DL, Worth A, et al. In vivo T lymphocyte dynamics in humans and the impact of human T-lymphotropic virus 1 infection. Proc Natl Acad Sci. 2007;104: 8035-8040. doi:10.1073/pnas.0608832104

11. Kuo Y-L, Giam C-Z. Activation of the anaphase promoting complex by HTLV-1 tax leads to senescence. EMBO J. 2006;25: 1741-1752. doi:10.1038/sj.emboj.7601054

12. Liang $\mathrm{M}-\mathrm{H}$, Geisbert $\mathrm{T}$, Yao $\mathrm{Y}$, Hinrichs $\mathrm{SH}$, Giam C-Z. Human T-Lymphotropic Virus Type 1 Oncoprotein Tax Promotes S-Phase Entry but Blocks Mitosis. J Virol. 2002;76: 4022-4033. doi:10.1128/JVI.76.8.4022-4033.2002

13. Liu M, Yang L, Zhang L, Liu B, Merling R, Xia Z, et al. Human T-Cell Leukemia Virus Type 1 Infection Leads to Arrest in the G1 Phase of the Cell Cycle. J Virol. 2008;82: 
8442-8455. doi:10.1128/JVI.00091-08

14. Zhi H, Yang L, Kuo Y-L, Ho Y-K, Shih H-M, Giam C-Z. NF-kB Hyper-Activation by HTLV-1 Tax Induces Cellular Senescence, but Can Be Alleviated by the Viral Anti-Sense Protein HBZ. PLOS Pathog. 2011;7: e1002025. doi:10.1371/journal.ppat.1002025

15. Copeland KF, Haaksma AG, Goudsmit J, Krammer PH, Heeney JL. Inhibition of apoptosis in T cells expressing human T cell leukemia virus type I Tax. AIDS Res Hum Retroviruses. 1994;10: 1259-1268. doi:10.1089/aid.1994.10.1259

16. Kawakami A, Nakashima T, Sakai H, Urayama S, Yamasaki S, Hida A, et al. Inhibition of Caspase Cascade by HTLV-I Tax Through Induction of NF-KB Nuclear Translocation. Blood. 1999;94: 3847-3854. doi:10.1182/blood.V94.11.3847

17. Brauweiler A, Garrus JE, Reed JC, Nyborg JK. Repression of Bax Gene Expression by the HTLV-I Tax Protein: Implications for Suppression of Apoptosis in Virally Infected Cells. Virology. 1997;231: 135-140. doi:10.1006/viro.1997.8509

18. Mühleisen A, Giaisi M, Köhler R, Krammer PH, Li-Weber M. Tax contributes apoptosis resistance to HTLV-1-infected T cells via suppression of Bid and Bim expression. Cell Death Dis. 2014;5: e1575. doi:10.1038/cddis.2014.536

19. Krueger A, Fas SC, Giaisi M, Bleumink M, Merling A, Stumpf C, et al. HTLV-1 Tax protects against CD95-mediated apoptosis by induction of the cellular FLICE-inhibitory protein (c-FLIP). Blood. 2006;107: 3933-3939. doi:10.1182/blood-2005-06-2567

20. Mahgoub M, Yasunaga J-I, Iwami S, Nakaoka S, Koizumi Y, Shimura K, et al. Sporadic on/off switching of HTLV-1 Tax expression is crucial to maintain the whole population of virus-induced leukemic cells. Proc Natl Acad Sci U S A. 2018;115: E1269-E1278. doi:10.1073/pnas.1715724115

21. Tsukahara T, Kannagi M, Ohashi $T$, Kato H, Arai M, Nunez G, et al. Induction of Bcl-xL Expression by Human T-Cell Leukemia Virus Type 1 Tax through NF-KB in ApoptosisResistant T-Cell Transfectants with Tax. J Virol. 1999;73: 7981-7987. doi:10.1128/JVI.73.10.7981-7987.1999

22. Wäldele K, Silbermann K, Schneider G, Ruckes T, Cullen BR, Grassmann R. 768 Requirement of the human T-cell leukemia virus (HTLV-1) tax-stimulated HIAP-1 gene for the survival of transformed lymphocytes. Blood. 2006;107: 4491-4499. doi:10.1182/blood-2005-08-3138

23. Chen X, Zachar V, Zdravkovic M, Guo M, Ebbesen P, Liu X. Role of the Fas/Fas ligand pathway in apoptotic cell death induced by the human $T$ cell lymphotropic virus type I Tax transactivator. J Gen Virol. 1997;78 ( Pt 12): 3277-3285. doi:10.1099/0022-131778-12-3277

24. Chlichlia K, Busslinger M, Peter ME, Walczak H, Krammer PH, Schirrmacher V, et al. ICE-proteases mediate HTLV-I Tax-induced apoptotic T-cell death. Oncogene. 1997;14: 
2265-2272. doi:10.1038/sj.onc. 1201070

25. Rivera-Walsh I, Waterfield M, Xiao G, Fong A, Sun S-C. NF-kB Signaling Pathway Governs TRAIL Gene Expression and Human T-cell Leukemia Virus-I Tax-induced Tcell Death *. J Biol Chem. 2001;276: 40385-40388. doi:10.1074/jbc.C100501200

26. Kao S-Y, Lemoine FJ, Marriott SJ. p53-Independent Induction of Apoptosis by the HTLV-I Tax Protein Following UV Irradiation. Virology. 2001;291: 292-298. doi:10.1006/viro.2001.1200

27. Kao S-Y, Lemoine FJ, Marriott SJ. HTLV-1 Tax protein sensitizes cells to apoptotic cell death induced by DNA damaging agents. Oncogene. 2000;19: 2240-2248. doi:10.1038/sj.onc.1203559

28. Cereseto A, Diella F, Mulloy JC, Cara A, Michieli P, Grassmann R, et al. p53 Functional Impairment and High p21waf1/cip1 Expression in Human T-Cell Lymphotropic/Leukemia Virus Type I -Transformed T Cells. Blood. 1996;88: 1551-1560. doi:10.1182/blood.V88.5.1551.1551

29. Baydoun HH, Bai XT, Shelton S, Nicot C. HTLV-I Tax Increases Genetic Instability by Inducing DNA Double Strand Breaks during DNA Replication and Switching Repair to NHEJ. PLOS ONE. 2012;7: e42226. doi:10.1371/journal.pone.0042226

30. Durkin SS, Guo X, Fryrear KA, Mihaylova VT, Gupta SK, Belgnaoui SM, et al. HTLV-1 Tax Oncoprotein Subverts the Cellular DNA Damage Response via Binding to DNAdependent Protein Kinase* J Biol Chem. 2008;283: 36311-36320. doi:10.1074/jbc.M804931200

31. He Y, Pasupala N, Zhi H, Dorjbal B, Hussain I, Shih H-M, et al. NF-kB-induced R-loop accumulation and DNA damage select for nucleotide excision repair deficiencies in adult T cell leukemia. Proc Natl Acad Sci. 2021;118: e2005568118-e2005568118. doi:10.1073/pnas.2005568118

32. Kinjo T, Ham-Terhune J, Peloponese J-M, Jeang K-T. Induction of Reactive Oxygen Species by Human T-Cell Leukemia Virus Type 1 Tax Correlates with DNA Damage and Expression of Cellular Senescence Marker. J Virol. 2010;84: 5431-5437. doi:10.1128/JVI.02460-09

33. Basbous J, Arpin C, Gaudray G, Piechaczyk M, Devaux C, Mesnard J-M. The HBZ Factor of Human T-cell Leukemia Virus Type I Dimerizes with Transcription Factors JunB and c-Jun and Modulates Their Transcriptional Activity*. J Biol Chem. 2003;278: 4362043627. doi:10.1074/jbc.M307275200

34. Gaudray G, Gachon F, Basbous J, Biard-Piechaczyk M, Devaux C, Mesnard J-M. The Complementary Strand of the Human T-Cell Leukemia Virus Type 1 RNA Genome Encodes a bZIP Transcription Factor That Down-Regulates Viral Transcription. J Virol. 2002;76: 12813-12822. doi:10.1128/JVI.76.24.12813-12822.2002 
35. Lemasson I, Lewis MR, Polakowski N, Hivin P, Cavanagh M-H, Thébault S, et al. Human T-Cell Leukemia Virus Type 1 (HTLV-1) bZIP Protein Interacts with the Cellular Transcription Factor CREB To Inhibit HTLV-1 Transcription. J Virol. 2007;81: 15431553. doi:10.1128/JVI.00480-06

36. Matsumoto A, Uesono Y. Physicochemical Solubility of and Biological Sensitivity to LongChain Alcohols Determine the Cutoff Chain Length in Biological Activity. Mol Pharmacol. 2018;94: 1312-1320. doi:10.1124/mol.118.112656

37. Zhao T, Yasunaga J, Satou Y, Nakao M, Takahashi M, Fujii M, et al. Human T-cell leukemia virus type $1 \mathrm{bZIP}$ factor selectively suppresses the classical pathway of NF-KB. Blood. 2009;113: 2755-2764. doi:10.1182/blood-2008-06-161729

38. Billman MR, Rueda D, Bangham CRM. Single-cell heterogeneity and cell-cycle-related viral gene bursts in the human leukaemia virus HTLV-1. Wellcome Open Res. 2017;2: 87. doi:10.12688/wellcomeopenres.12469.2

39. Miura M, Dey S, Ramanayake S, Singh A, Rueda DS, Bangham CRM. Kinetics of HTLV1 reactivation from latency quantified by single-molecule RNA FISH and stochastic modelling. PLOS Pathog. 2019;15: e1008164. doi:10.1371/journal.ppat.1008164

40. Cook LB, Rowan AG, Melamed A, Taylor GP, Bangham CRM. HTLV-1-infected T cells contain a single integrated provirus in natural infection. Blood. 2012;120: 3488-3490. doi:10.1182/blood-2012-07-445593

41. Subach FV, Subach OM, Gundorov IS, Morozova KS, Piatkevich KD, Cuervo AM, et al. Monomeric fluorescent timers that change color from blue to red report on cellular trafficking. Nat Chem Biol. 2009;5: 118-126. doi:10.1038/nchembio.138

42. Bending D, Prieto Martín P, Paduraru A, Ducker C, Marzaganov E, Laviron M, et al. A timer for analyzing temporally dynamic changes in transcription during differentiation in vivo. J Cell Biol. 2018;217: 2931-2950. doi:10.1083/jcb.201711048

43. Bending D, Paduraru A, Ducker CB, Prieto Martín P, Crompton T, Ono M. A temporally dynamic Foxp3 autoregulatory transcriptional circuit controls the effector Treg programme. EMBO J. 2018;37: e99013. doi:10.15252/embj.201899013

44. Rende F, Cavallari I, Corradin A, Silic-Benussi M, Toulza F, Toffolo GM, et al. Kinetics and intracellular compartmentalization of HTLV-1 gene expression: nuclear retention of HBZ mRNAs. Blood. 2011;117: 4855-4859. doi:10.1182/blood-2010-11-316463

45. Yoshida M, Satou Y, Yasunaga J, Fujisawa J, Matsuoka M. Transcriptional Control of Spliced and Unspliced Human T-Cell Leukemia Virus Type 1 bZIP Factor (HBZ) Gene. J Virol. 2008 [cited 22 Dec 2021]. doi:10.1128/JVI.00242-08

46. Chung H-K, Young HA, Goon PKC, Heidecker G, Princler GL, Shimozato O, et al. Activation of interleukin-13 expression in T cells from HTLV-1-infected individuals and in chronically infected cell lines. Blood. 2003;102: 4130-4136. doi:10.1182/blood-2003-04- 
47. Fujii M, Niki T, Mori T, Matsuda $T$, Matsui $M$, Nomura $N$, et al. HTLV-1 Tax induces expression of various immediate early serum responsive genes. Oncogene. 1991;6: 1023-1029.

48. Hieshima K, Nagakubo D, Nakayama T, Shirakawa A-K, Jin Z, Yoshie O. Tax-inducible production of CC chemokine ligand 22 by human T cell leukemia virus type 1 (HTLV-1)infected T cells promotes preferential transmission of HTLV-1 to CCR4-expressing CD4+ T cells. J Immunol Baltim Md 1950. 2008;180: 931-939. doi:10.4049/jimmunol.180.2.931

49. Inoue J, Seiki M, Taniguchi T, Tsuru S, Yoshida M. Induction of interleukin 2 receptor gene expression by p40x encoded by human T-cell leukemia virus type 1 . EMBO J. 1986;5: 2883-2888.

862

50. Lemasson I, Robert-Hebmann V, Hamaia S, Duc Dodon M, Gazzolo L, Devaux C. Transrepression of Ick gene expression by human T-cell leukemia virus type 1-encoded p40tax. J Virol. 1997;71: 1975-1983. doi:10.1128/JVI.71.3.1975-1983.1997

51. Jiang $H$, Lu H, Schiltz RL, Pise-Masison CA, Ogryzko VV, Nakatani $Y$, et al. PCAF 866 Interacts with Tax and Stimulates Tax Transactivation in a Histone AcetyltransferaseIndependent Manner. Mol Cell Biol. 1999 [cited 8 Feb 2022]. doi:10.1128/MCB.19.12.8136

52. Liberzon A, Birger C, Thorvaldsdóttir H, Ghandi M, Mesirov JP, Tamayo P. The Molecular Signatures Database Hallmark Gene Set Collection. Cell Syst. 2015;1: 417-425. doi:10.1016/j.cels.2015.12.004

53. Boxus $M$, Willems $L$. How the DNA damage response determines the fate of HTLV-1 Tax-expressing cells. Retrovirology. 2012;9: 2-2. doi:10.1186/1742-4690-9-2

54. Kusakabe M, Onishi $\mathrm{Y}$, Tada H, Kurihara F, Kusao K, Furukawa M, et al. Mechanism and regulation of DNA damage recognition in nucleotide excision repair. Genes Environ. 2019;41: 2. doi:10.1186/s41021-019-0119-6

55. Kao S-Y, Lemoine FJ, Marriott SJ. Suppression of DNA Repair by Human T Cell Leukemia Virus Type 1 Tax Is Rescued by a Functional p53 Signaling Pathway *. J Biol Chem. 2000;275: 35926-35931. doi:10.1074/jbc.M004397200

56. Kao S-Y, Marriott SJ. Disruption of Nucleotide Excision Repair by the Human T-Cell Leukemia Virus Type 1 Tax Protein. J Virol. 1999;73: 4299-4304. doi:10.1128/JVI.73.5.4299-4304.1999

57. Galluzzi L, Vitale I, Aaronson SA, Abrams JM, Adam D, Agostinis P, et al. Molecular mechanisms of cell death: recommendations of the Nomenclature Committee on Cell Death 2018. Cell Death Differ. 2018;25: 486-541. doi:10.1038/s41418-017-0012-4 
902

903

904

905

906

907

908

909

910

911

912

913

914

915

916

917

918

919

920

921

922

923

Infection. PLOS Pathog. 2013;9: e1003271. doi:10.1371/journal.ppat.1003271

59. Kulkarni A, Mateus M, Thinnes CC, McCullagh JS, Schofield CJ, Taylor GP, et al. Glucose Metabolism and Oxygen Availability Govern Reactivation of the Latent Human Retrovirus HTLV-1. Cell Chem Biol. 2017;24: 1377-1387.e3. doi:10.1016/j.chembiol.2017.08.016

60. Hong W, Cheng W, Zheng T, Jiang N, Xu R. AHR is a tunable knob that controls HTLV1 latency-reactivation switching. Harhaj EW, editor. PLOS Pathog. 2020;16: e1008664e1008664. doi:10.1371/journal.ppat.1008664

61. Kulkarni A, Taylor GP, Klose RJ, Schofield CJ, Bangham CR. Histone H2A monoubiquitylation and $\mathrm{p38-MAPKs}$ regulate immediate-early gene-like reactivation of latent retrovirus HTLV-1. JCI Insight. 2018;3: 123196. doi:10.1172/jci.insight.123196

62. Cohen I, Bar C, Ezhkova E. Activity of PRC1 and Histone H2AK119 Monoubiquitination: Revising Popular Misconceptions. BioEssays. 2020;42: 1900192. doi:10.1002/bies.201900192

63. Harper PA, Riddick DS, Okey AB. Regulating the regulator: Factors that control levels and activity of the aryl hydrocarbon receptor. Biochem Pharmacol. 2006;72: 267-279. doi:10.1016/j.bcp.2006.01.007

64. Rothhammer V, Quintana FJ. The aryl hydrocarbon receptor: an environmental sensor integrating immune responses in health and disease. Nat Rev Immunol. 2019;19: 184197. doi:10.1038/s41577-019-0125-8

65. Zhou Y-H, Sun L, Chen J, Sun W-W, Ma L, Han Y, et al. Tryptophan Metabolism Activates Aryl Hydrocarbon Receptor-Mediated Pathway To Promote HIV-1 Infection and Reactivation. mBio. 2019 [cited 2 Feb 2022]. doi:10.1128/mBio.02591-19

66. Song J, Clagett-Dame M, Peterson RE, Hahn ME, Westler WM, Sicinski RR, et al. A ligand for the aryl hydrocarbon receptor isolated from lung. Proc Natl Acad Sci U S A. 2002;99: 14694-14699. doi:10.1073/pnas.232562899

67. Rannug U, Rannug A, Sjöberg U, Li H, Westerholm R, Bergman J. Structure elucidation of two tryptophan-derived, high affinity Ah receptor ligands. Chem Biol. 1995;2: 841-845. doi:10.1016/1074-5521(95)90090-x

68. Boitano AE, Wang J, Romeo R, Bouchez LC, Parker AE, Sutton SE, et al. Aryl hydrocarbon receptor antagonists promote the expansion of human hematopoietic stem cells. Science. 2010;329: 1345-1348. doi:10.1126/science.1191536

69. Zhao B, Degroot DE, Hayashi A, He G, Denison MS. CH223191 is a ligand-selective antagonist of the Ah (Dioxin) receptor. Toxicol Sci Off J Soc Toxicol. 2010;117: 393-403. doi:10.1093/toxsci/kfq217

70. Sharma R, Williams IS, Gatchie L, Sonawane VR, Chaudhuri B, Bharate SB. Khellinoflavanone, a Semisynthetic Derivative of Khellin, Overcomes Benzo[a]pyrene 
Toxicity in Human Normal and Cancer Cells That Express CYP1A1. ACS Omega. 2018;3: 8553-8566. doi:10.1021/acsomega.8b01088

71. Satou Y, Yasunaga J, Yoshida M, Matsuoka M. HTLV-I basic leucine zipper factor gene mRNA supports proliferation of adult T cell leukemia cells. Proc Natl Acad Sci U S A. 2006;103: 720-725. doi:10.1073/pnas.0507631103

930

72. Harhaj EW, Giam C-Z. NF-KB signaling mechanisms in HTLV-1-induced adult T-cell leukemia/lymphoma. FEBS J. 2018;285: 3324-3336. doi:10.1111/febs.14492

73. Mori N, Fujii M, Ikeda S, Yamada Y, Tomonaga M, Ballard DW, et al. Constitutive Activation of NF-kB in Primary Adult T-Cell Leukemia Cells. Blood. 1999;93: 2360-2368. doi:10.1182/blood.V93.7.2360

74. Sun SC, Elwood J, Béraud C, Greene WC. Human T-cell leukemia virus type I Tax activation of NF-kappa B/Rel involves phosphorylation and degradation of I kappa B alpha and RelA (p65)-mediated induction of the c-rel gene. Mol Cell Biol. 1994 [cited 13 Jan 2022]. doi:10.1128/mcb.14.11.7377-7384.1994

939

75. Huang $Y$, Ohtani $K$, Iwanaga R, Matsumura $Y$, Nakamura M. Direct trans-activation of the human cyclin D2 gene by the oncogene product Tax of human T-cell leukemia virus type I. Oncogene. 2001;20: 1094-1102. doi:10.1038/sj.onc.1204198

76. Iwanaga R, Ohtani K, Hayashi T, Nakamura M. Molecular mechanism of cell cycle progression induced by the oncogene product Tax of human T-cell leukemia virus type I. Oncogene. 2001;20: 2055-2067. doi:10.1038/sj.onc.1204304

77. Lemasson I, Thébault S, Sardet C, Devaux C, Mesnard J-M. Activation of E2F-mediated Transcription by Human T-cell Leukemia Virus Type I Tax Protein in a p16INK4Anegative T-cell Line* J Biol Chem. 1998;273: 23598-23604. doi:10.1074/jbc.273.36.23598

78. Mori N, Fujii M, Hinz M, Nakayama K, Yamada Y, Ikeda S, et al. Activation of cyclin D1 and D2 promoters by human T-cell leukemia virus type I tax protein is associated with IL-2-independent growth of $T$ cells. Int $J$ Cancer. 2002;99: 378-385. doi:10.1002/ijc.10388

79. Ohtani K, Iwanaga R, Arai M, Huang Y, Matsumura Y, Nakamura M. Cell Type-specific E2F Activation and Cell Cycle Progression Induced by the Oncogene Product Tax of Human T-cell Leukemia Virus Type I*. J Biol Chem. 2000;275: 11154-11163. doi:10.1074/jbc.275.15.11154

80. Santiago F, Clark E, Chong S, Molina C, Mozafari F, Mahieux R, et al. Transcriptional Up-Regulation of the Cyclin D2 Gene and Acquisition of New Cyclin-Dependent Kinase Partners in Human T-Cell Leukemia Virus Type 1-Infected Cells. J Virol. 1999;73: 99179927.

81. Mulloy JC, Kislyakova T, Cereseto A, Casareto L, LoMonico A, Fullen J, et al. Human T- 
Cell Lymphotropic/Leukemia Virus Type 1 Tax Abrogates p53-Induced Cell Cycle Arrest and Apoptosis through Its CREB/ATF Functional Domain. J Virol. 1998;72: 8852-8860. doi:10.1128/JVI.72.11.8852-8860.1998

82. Farcas AM, Blackledge NP, Sudbery I, Long HK, McGouran JF, Rose NR, et al. KDM2B links the Polycomb Repressive Complex 1 (PRC1) to recognition of $\mathrm{CpG}$ islands. Struhl K, editor. eLife. 2012;1: e00205. doi:10.7554/eLife.00205

968

969

970

971

972

973

974

975

976

977

978

979

980

981

982

983

984

985

986

987

988

989

990

991

992

993

994

995

996

997

998

83. Rose NR, King HW, Blackledge NP, Fursova NA, Ember KJ, Fischer R, et al. RYBP stimulates PRC1 to shape chromatin-based communication between Polycomb repressive complexes. Verrijzer P, editor. elife. 2016;5: e18591. doi:10.7554/eLife.18591

84. Hayashibara T, Yamada Y, Mori N, Harasawa H, Sugahara K, Miyanishi T, et al. Possible involvement of aryl hydrocarbon receptor (AhR) in adult T-cell leukemia (ATL) leukemogenesis: constitutive activation of AhR in ATL. Biochem Biophys Res Commun. 2003;300: 128-134. doi:10.1016/S0006-291X(02)02793-6

85. Fujisawa J, Toita M, Yoshida M. A unique enhancer element for the trans activator (p40tax) of human T-cell leukemia virus type I that is distinct from cyclic AMP- and 12O-tetradecanoylphorbol-13-acetate-responsive elements. J Virol. 1989;63: 3234-3239. doi:10.1128/JVI.63.8.3234-3239.1989

86. Zhang L, Liu M, Merling R, Giam C-Z. Versatile reporter systems show that transactivation by human T-cell leukemia virus type 1 Tax occurs independently of chromatin remodeling factor BRG1. J Virol. 2006;80: 7459-7468. doi:10.1128/JVI.00130-06

87. Cikos S, Bukovská A, Koppel J. Relative quantification of mRNA: comparison of methods currently used for real-time PCR data analysis. BMC Mol Biol. 2007;8: 113. doi:10.1186/1471-2199-8-113

88. Satou $\mathrm{Y}$, Miyazato $\mathrm{P}$, Ishihara K, Yaguchi H, Melamed A, Miura M, et al. The retrovirus HTLV-1 inserts an ectopic CTCF-binding site into the human genome. Proc Natl Acad Sci. 2016;113: 3054-3059. doi:10.1073/pnas.1423199113

89. Lin $\mathrm{P}, \mathrm{Hu} \mathrm{S}-\mathrm{W}$, Chang $\mathrm{T}-\mathrm{H}$. Correlation between gene expression of aryl hydrocarbon receptor (AhR), hydrocarbon receptor nuclear translocator (Arnt), cytochromes P4501A1 (CYP1A1) and 1B1 (CYP1B1), and inducibility of CYP1A1 and CYP1B1 in human lymphocytes. Toxicol Sci Off J Soc Toxicol. 2003;71: 20-26. doi:10.1093/toxsci/71.1.20

90. R Core Team. R: A Language and Environment for Statistical Computing. Vienna, Austria: R Foundation for Statistical Computing; 2021.

91. Dobin A, Davis CA, Schlesinger F, Drenkow J, Zaleski C, Jha S, et al. STAR: Ultrafast universal RNA-seq aligner. Bioinformatics. 2013;29: 15-21. doi:10.1093/bioinformatics/bts635 
92. Li B, Dewey CN. RSEM: accurate transcript quantification from RNA-Seq data with or without a reference genome. BMC Bioinformatics. 2011;12: 323. doi:10.1186/1471-210512-323

93. Soneson C, Love MI, Robinson MD. Differential analyses for RNA-seq: transcript-level estimates improve gene-level inferences. F1000Research; 2016. doi:10.12688/f1000research.7563.2

1005

94. Love Ml, Huber W, Anders S. Moderated estimation of fold change and dispersion for RNA-seq data with DESeq2. Genome Biol. 2014;15: 550. doi:10.1186/s13059-014-05508

95. Benjamini Y, Hochberg Y. Controlling the False Discovery Rate: A Practical and Powerful Approach to Multiple Testing. J R Stat Soc Ser B Methodol. 1995;57: 289-300.

96. Anders S, Huber W. Differential expression analysis for sequence count data. Genome Biol. 2010;11: R106. doi:10.1186/gb-2010-11-10-r106

97. Raudvere U, Kolberg L, Kuzmin I, Arak T, Adler P, Peterson H, et al. g:Profiler: a web server for functional enrichment analysis and conversions of gene lists (2019 update). Nucleic Acids Res. 2019;47: W191-W198. doi:10.1093/nar/gkz369 
1015 Supporting information captions

1016 S1 Fig. Schematic of provirus in 3.60. Schematic of the provirus in clone 3.60 with the 202 bp deletion

1017 and coding-regions of Env, Tax and sHBZ marked.

1018 S2 Fig. Volcano plots of genes deregulated between early burst and silent and late burst

1019 phases. Significantly up-regulated genes are in yellow and down-regulated genes in blue. HTLV-1 plus, Timer

1020 and top 10 most significantly up- and down-regulated genes are labelled; ns - not significant.

1021 S3 Fig. Gene trajectories of genes mentioned in main text. Y-axis: normalized counts on log10-

1022 scale. Significance is determined with LRT. FDR-corrected p-value $<0.01$.

1023 S4 Fig. NF-KB pathway is significantly up-regulated in each clone. (A) K-means clustering of 102410048 significantly DE genes with $\mathrm{k}=2$ in clone 3.60 and 4798 DE genes in clone TBX4B. The top 10 genes based on mean rank of sorted p-values are listed on the right in each panel. The mean expression trajectory is coloured yellow or blue.

1027 Significance is determined with LRT. FDR-corrected p-value $<0.01$. (B) Over-representation analysis of K-means 1028 clusters with the Hallmarks gene set from The Molecular Signatures Database (MSigDB). Statistical significance 1029 was determined by Fisher's exact test in g:Profiler. FDR-corrected p-value $<0.05$.

1030 S1 Data. Differential expression results for clone 3.60.

1031 S2 Data. Differential expression results for clone TBX4B.

1032 S3 Data. AhR measurements 

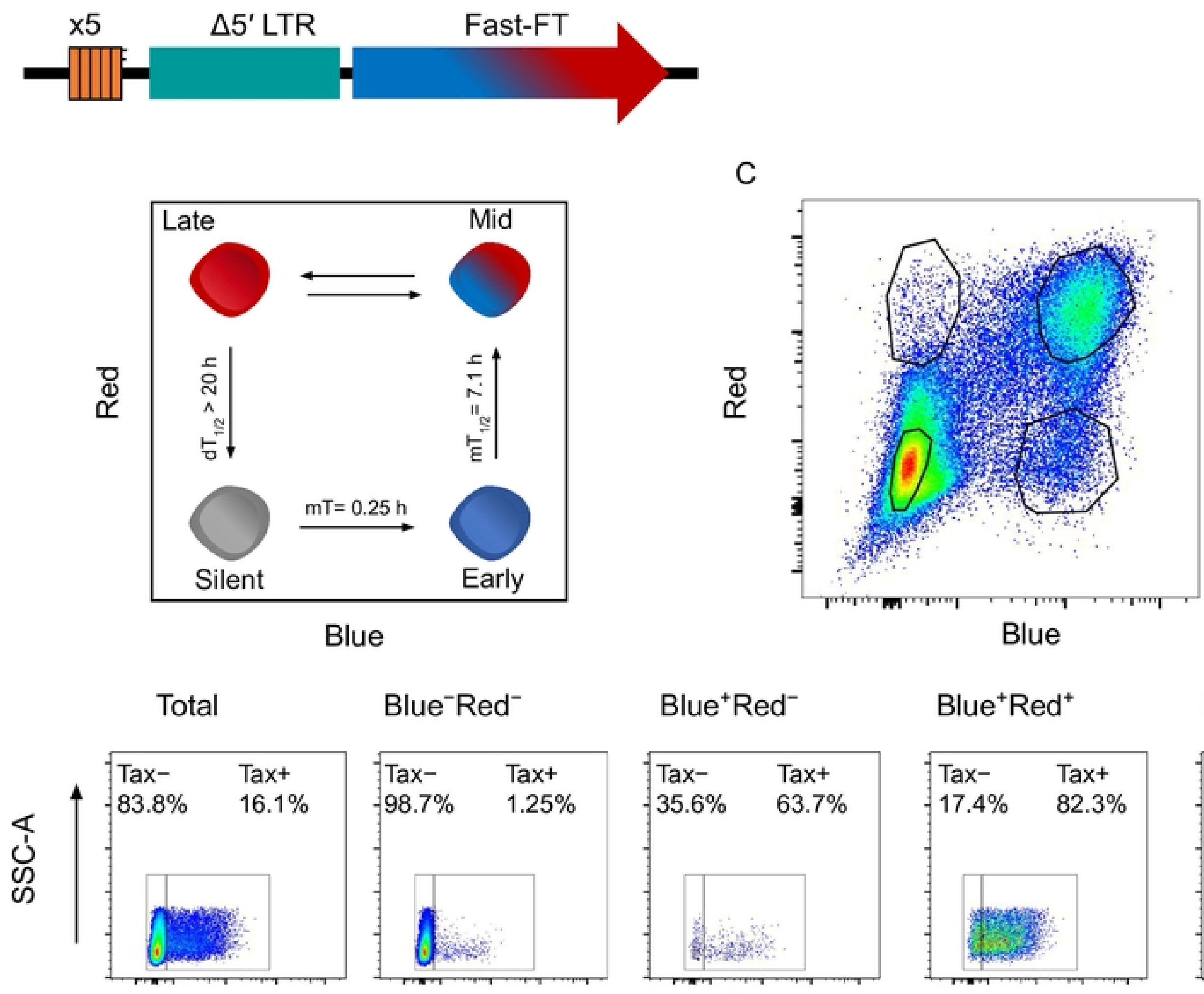

\section{Blue $^{+}$Red $^{-}$}

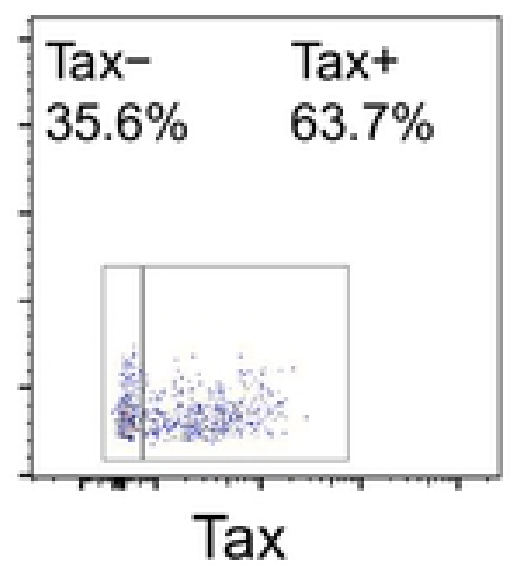

Blue $^{+}$Red $^{+}$

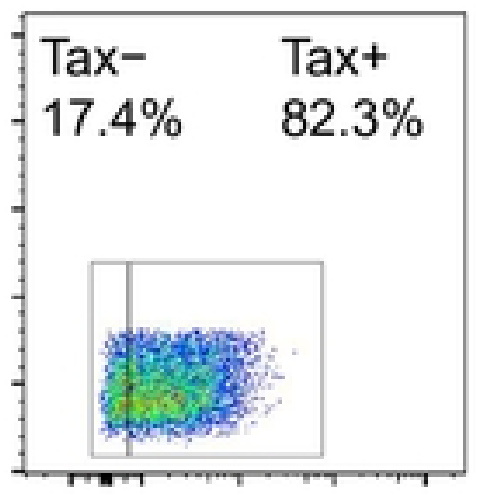

Blue $^{-}$Red $^{+}$

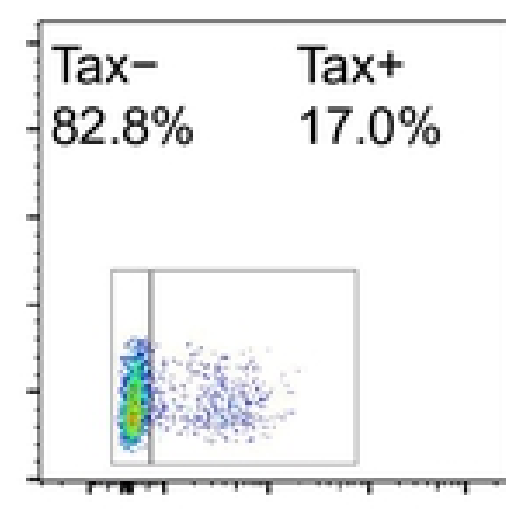

Figure 1 

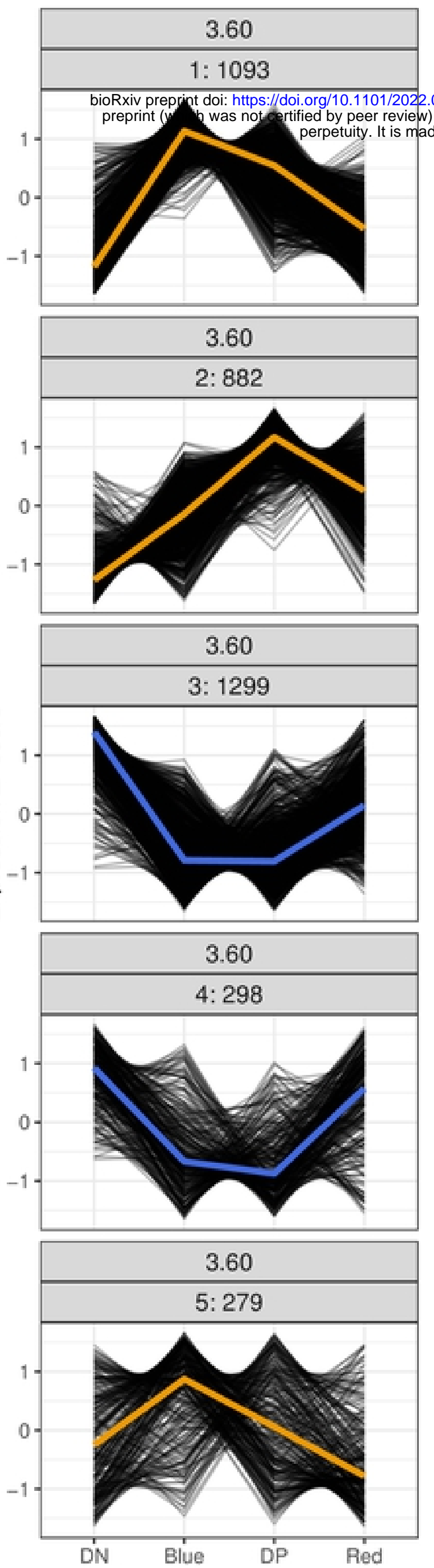

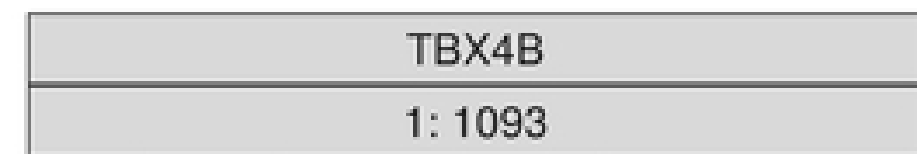

1: 1093
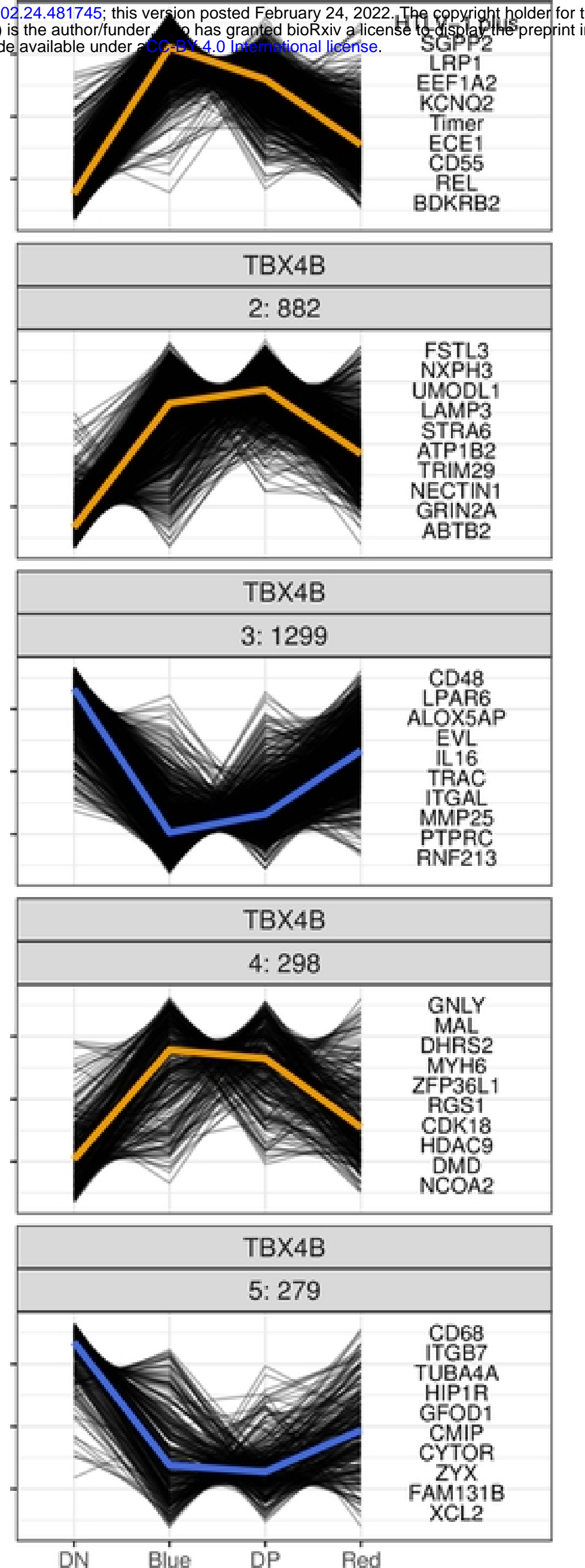

Timer protein phase

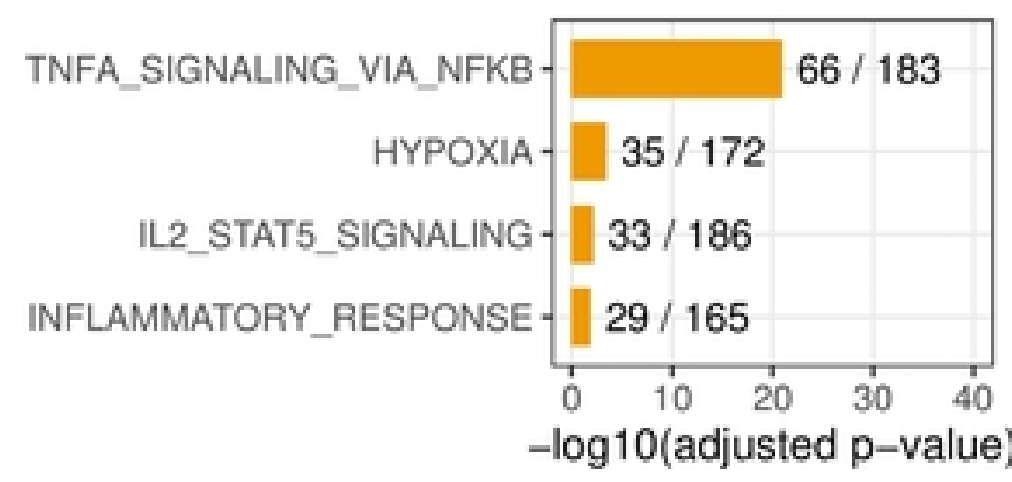

Gene cluster 2

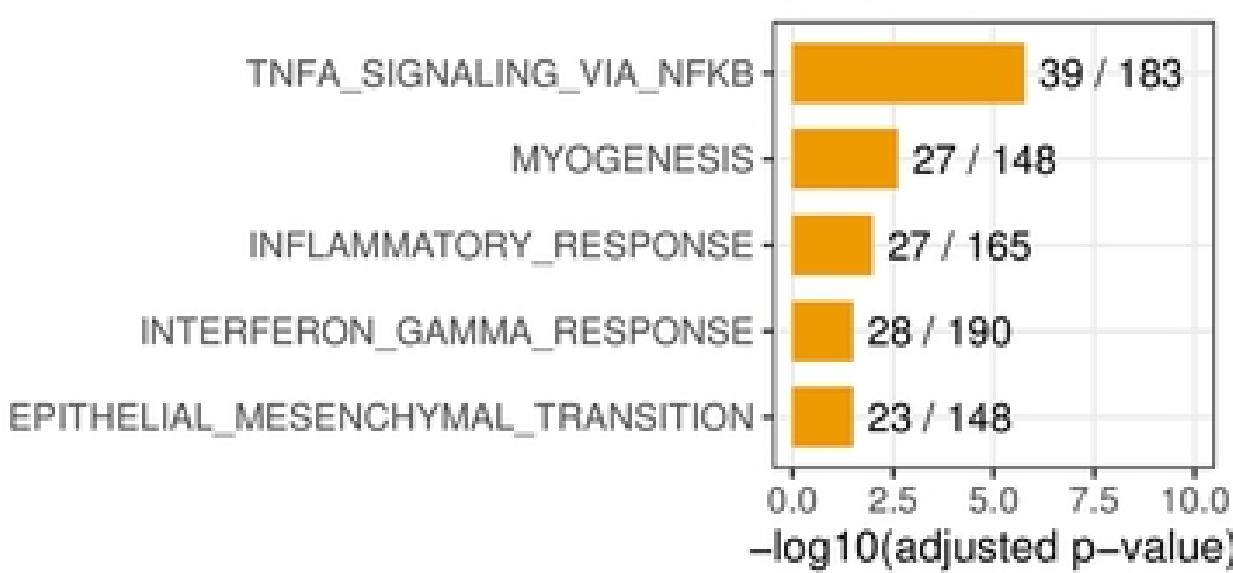

Gene cluster 3

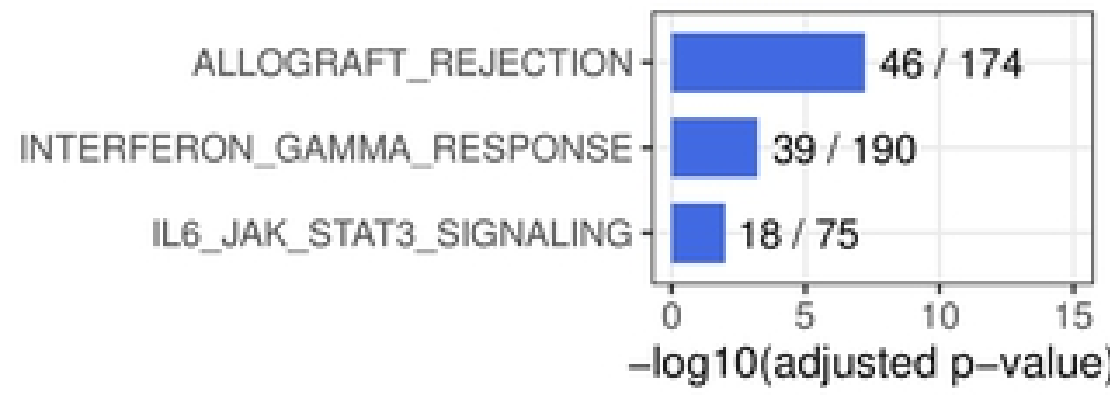

Gene cluster 4

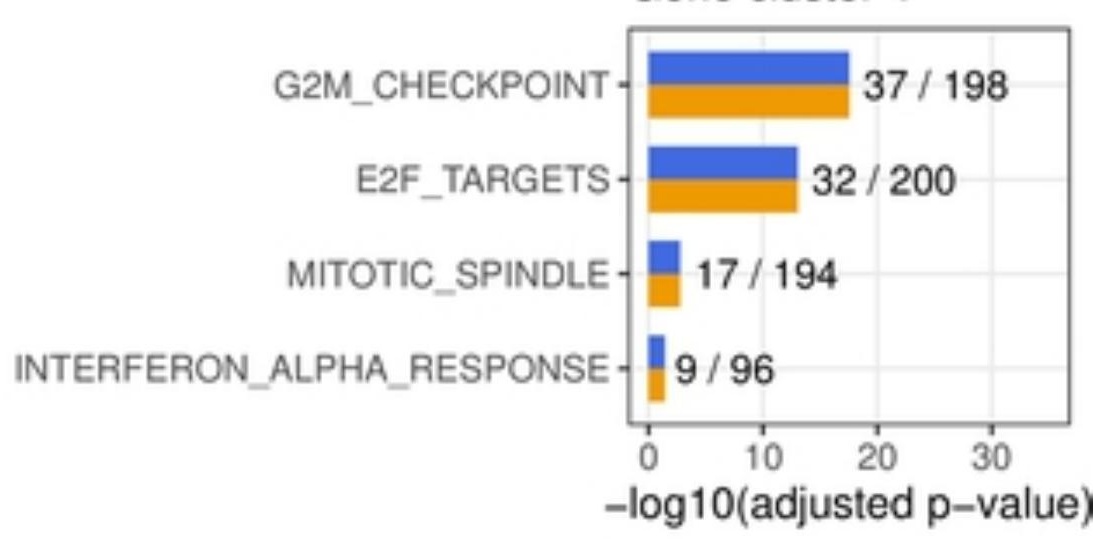

\section{Figure 3}



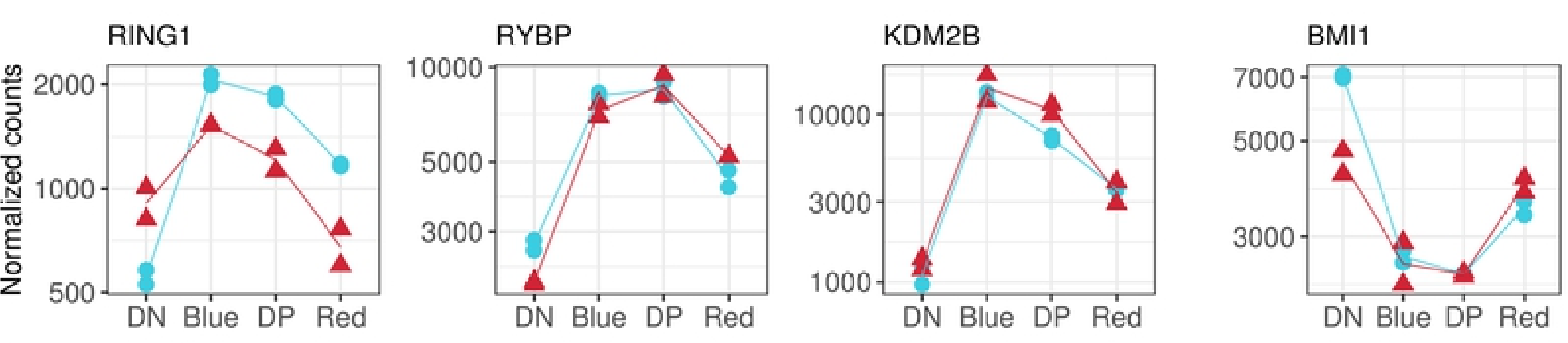

Clones

- 3.60

- TBX4B

Figure 7 

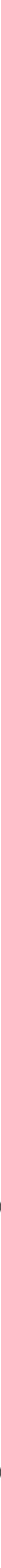

Figure 8

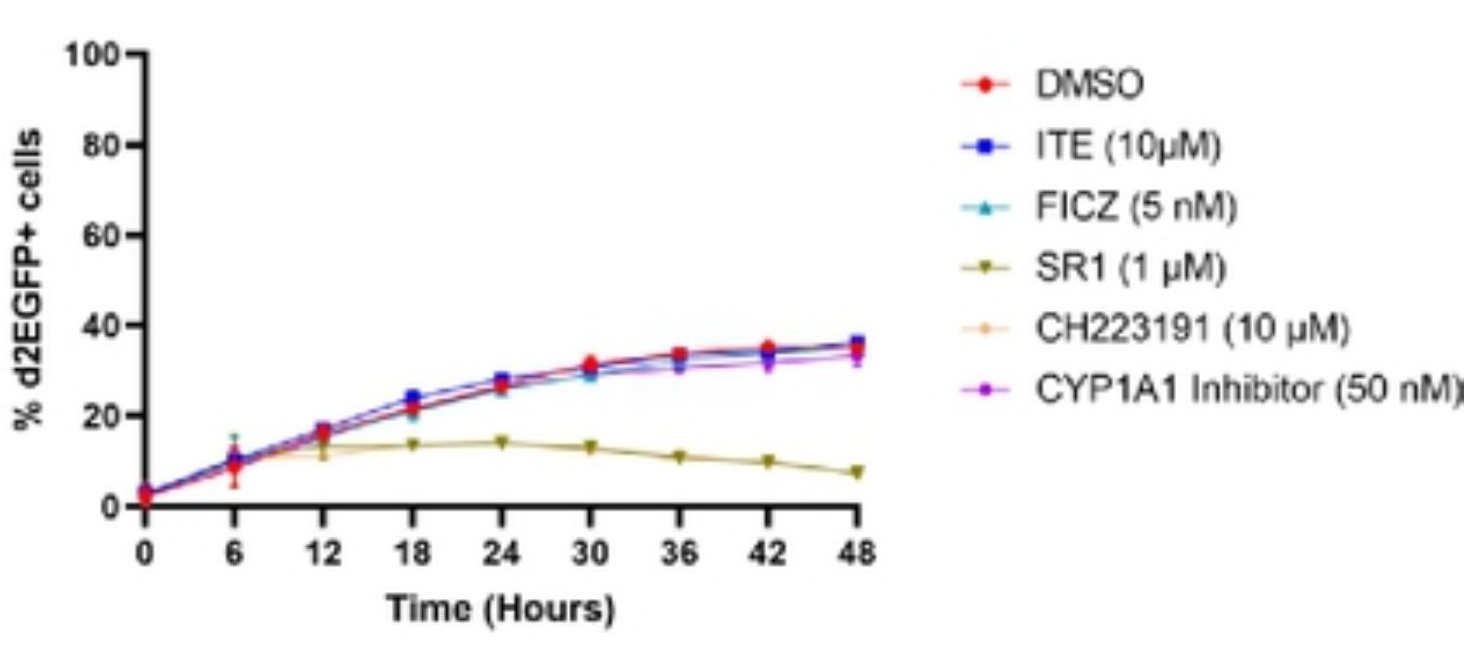

